\title{
EL TIFUS DE LOS ASILOS. GESTIÓN MUNICIPAL Y REPERCUSIONES SOCIALES DE UNA CATÁSTROFE HIGIÉNICO-SANITARIA EN MADRID A PRINCIPIOS DEL SIGLO XX ${ }^{*}$
}

\author{
The Typhus of the Asylums. Local Management and \\ Social Consequences of an Hygienic-Sanitary Catastrophe \\ in Madrid at the Beginning of the $20^{\text {th }}$ Century
}

Santiago de Miguel Salanova sdmiguel@ghis.ucm.es Universidad Complutense de Madrid. España

Fecha de recepción: 31/07/2017

Fecha de aceptación: 05/12/2017

Resumen: A comienzos del novecientos, y a diferencia de lo que ocurría en otras grandes ciudades europeas, Madrid era una urbe todavía asolada por graves problemas sanitarios que ocasionaban incrementos sistemáticos en sus tasas de mortalidad. A pesar de que desde mediados del siglo anterior existía una preocupación teórica cada vez más intensa con respecto a los embates epidémicos que golpeaban a sus contingentes poblacionales (sobre todo por parte de los médicos higienistas), éstos seguían emergiendo al compás de las deficientes actuaciones de las altas instancias estatales y municipales en materia de sanidad. El presente artículo aborda esta cuestión a partir de un caso de estudio específico: la primera epidemia de tifus exantemático acaecida en la capital española a finales de abril de 1903 y prolongada hasta 1905. A partir de una variada documentación de archivo (Libros de Filiación del Hospital Provincial, Libros de Defunciones y Estadísticas Demográficas del

* Este artículo ha sido realizado en el marco del proyecto nacional I+D «La sociedad urbana en la España del primer tercio del siglo xx. Madrid y Bilbao, vanguardia de la modernidad, 19001936», en el marco del Programa Estatal de Fomento de la Investigación Científica y Técnica de Excelencia del Ministerio de Economía y Competitividad (ref. HAR2015-65134-C2-1-P). Su autor ha contado igualmente con la ayuda proporcionada en el marco del Programa de Atracción de Talento de la Comunidad de Madrid, 2017, Modalidad 2 (Ficha 2017-T2/HUM-5216) 
Ayuntamiento de Madrid, publicaciones especializadas de la época y prensa periódica), se analizarán las características de la lucha contra esta enfermedad durante su evolución y sus repercusiones sobre el plano social y residencial.

Palabras clave: Madrid; Higiene; Sanidad Pública; Asilos; Tifus exantemático.

\begin{abstract}
At the beginning of the twentieth century, unlike in other major European cities, Madrid was still plagued by serious health problems that caused systematic and constant increases in their mortality rates. Despite the fact that since the middle of the previous century there was a growing concern about the epidemics affecting the inhabitants of the city (especially by the hygienists), these continued to emerge in the midst of the poor performances of state and municipal authorities in terms of public health. This paper addresses this issue from a specific case study: the first epidemic of exanthematous typhus occurred in Madrid at the end of April 1903 and extended until 1905. Drawing on a varied documentation that comprises filiation books of the Provincial Hospital of Madrid, death yearbooks and demographic statistics of Madrid City Council, specialized publications of the period and periodical press; this work will analyse the characteristics of the official fight against this disease during its evolution, as well as its repercussions on the social and residential level.
\end{abstract}

Keywords: Madrid; Hygiene; Public Health; Asylums; Exanthematous Typhus.

SUMARIO: 1. Introducción. 2. El nacimiento de un pleito médico-sanitario. 3. La zona cero del tifus exantemático en Madrid y la organización inicial de la campaña sanitaria. 4. La compleja superación del primer brote epidémico. 5. El recrudecimiento de la epidemia en 1904 y su fase final en 1905. 6. Conclusiones. 7. Bibliografía.

\title{
1. INTRODUCCIÓN
}

A principios del siglo xx, Madrid era categorizada por buena parte de la prensa y de la literatura higienista como La Ciudad de la Muerte (Belmás, 1882; Méndez Álvaro, 1882; Jimeno, 1886; Úbeda, 1900; Revenga, 1901 y Hauser, 1902). Permanecía estancada en un ciclo demográfico antiguo, definido por altas tasas de natalidad y mortalidad, un crecimiento natural bajo e incluso negativo en ciertos años y crisis de sobremortalidad vehiculadas por severos embates epidémicos (Fernández García, 2001 y Porras Gallo, 2002). Su incremento poblacional respondía, fundamentalmente, a la sistemática recepción de contingentes migratorios llegados de todo el país (Pallol, 2015; Vicente, 2015; Carballo, 2015; De Miguel, 2016 y Díaz, 2016). Sin embargo, esa expansión humana fue en detrimento de sus atributos sanitarios. Durante el último cuarto del ochocientos, la ciudad corroboró un abandono de unas modernas prácticas médicas e higienistas por parte de sus instituciones oficiales que cristalizó en diversas catástrofes sanitarias (Fernández García, 1985).

Gran parte de lo que ocurría en Madrid se explicaba por su atraso con respecto a otras capitales europeas en cuanto concierne al interés estatal, provincial y municipal por la higiene como medida profiláctica (Bernabéu-Mestre y Galiana, 2011). Como señala Cañedo, la sucesión de epidemias a lo largo del siglo XIX exigió 
respuestas cada vez más precisas por parte de sus instituciones políticas y administrativas, abriéndose el camino hacia lo que define como una «medicalización del espacio urbano» (Cañedo, 2012). Sin embargo, este proceso resultó más arduo y complejo que en el resto de Europa, como refleja Hudemann-Simon (HudemannSimon, 2017). Su estudio muestra el desarrollo de comisiones sanitarias en Prusia a finales del primer tercio del ochocientos tras el primer brote de cólera, encargadas de transmitir indicaciones sobre el control de la epidemia; la proliferación de leyes y servicios de sanidad pública cada vez más avanzadas en Inglaterra, al son del cambio de escala que experimentaron los problemas de higiene urbana con la proliferación de barrios bajos superpoblados; y la existencia de precoces políticas de una higiene pública racional en Francia e Italia, donde se crearon cátedras sanitarias, consejos de salubridad y leyes colectivas para luchar contra las enfermedades contagiosas.

España no se mantuvo al margen de los avances que en términos de higiene científica se producían en el resto de Europa (Alcaide, 1999 y Rodríguez Ocaña, 2001). Influenciados por postulados intelectuales ilustrados de finales del siglo XVIII, diversos especialistas médicos, entre los que cabría destacar a Pedro Felipe Monlau, Mateo Seoane y Francisco Méndez Álvaro, se preocuparon por aspectos relacionados con el entorno, el hábitat y las condiciones de salubridad de la población (Moro, 1986; Rodríguez Ocaña, 1992 y Cuñat, 2011). Para confirmar este interés, basta con analizar los estudios que siguieron el impacto de determinadas enfermedades y epidemias en las principales ciudades del país planteando, al mismo tiempo, medidas preventivas aplicables a situaciones análogas en el futuro (Lartiga, 1854; González, 1854; Díaz, 1865 y Jimeno, 1886). Sin embargo, la creciente representatividad del movimiento higienista en España estuvo desacompasada con unos planes de acción estatal y municipal insuficientes para afrontar con garantías el creciente impacto de las enfermedades infecto-contagiosas sobre el tejido urbano. Esta descoordinación fue especialmente sangrante en Madrid, donde la inoperancia de las autoridades para establecer procedimientos de defensa ante la aparición de epidemias quedó reflejada en dramáticos brotes como los del cólera en $1834,1854,1865$ y 1885 o el de viruela de 1890, coexistente con otros dos de gripe y sarampión (Fernández García, 1979; Puerto, 1980; Urquijo, 1983; Díaz, 2014 y García Ferrero, 2017).

En los albores del novecientos, Madrid no había mejorado un ápice sus carencias higiénico-sanitarias. Por el contrario, las había amplificado. Continuaba siendo víctima de epidemias periódicas, entre las que destacaron la de tifus exantemático de 1903 abordada en este artículo (reproducida de nuevo seis años más tarde), junto a otras de viruela $(1900,1903-1904$ y 1909) y fiebre tifoidea (1909). Todas podrían haberse atenuado con actuaciones más enérgicas de la administración pública. No en vano, su expansión fue deudora de problemas urbanos como una inaudita aglomeración de viviendas en espacios del casco antiguo que a todas luces exigían 
una inmediata reforma; la ausencia de una legislación de casas baratas orientada a la clase obrera; las deficiencias de un sistema de alcantarillado incompleto que seguía combinándose con la utilización de pozos negros de evacuación; un servicio de limpiezas atrasado y un constante incumplimiento de las ordenanzas municipales de 1892 que debían velar por el buen estado de los artículos de primera necesidad consumidos por los habitantes (De Miguel, 2017).

Pero uno de los abandonos municipales más clamorosos se relacionaba con el problema de la mendicidad, crónico desde mediados del ochocientos (Bahamonde y Toro, 1978). Madrid se convirtió en el principal foco de atracción para inmigrantes de las provincias limítrofes que llegaban escapando del hambre, pero las oportunidades laborales que esperaban encontrar en la ciudad eran, en la mayoría de los casos, ilusorias, lo que les llevaba a verse impelidos a la caridad (Vidal, 1992; Pinto, 2002 y López Castellano, 2010). Las autoridades locales afrontaron el problema coartadas por raquíticas dotaciones presupuestarias y por la falta de las subvenciones estatales que otros países europeos concedían a sus grandes núcleos urbanos en concepto de capitalidad. Año tras año, Madrid reproducía el mismo esquema durante los meses de invierno. La fragilidad de un mercado laboral cada vez más proletarizado generaba entonces repuntes muy significativos en las cifras de parados. El consistorio respondía a este dilema social con contrataciones temporales para la realización de obras públicas que ni mucho menos lo solventaban. A su vez, estas fases coincidían con grandes incrementos en las cifras de mendigos a sostener mediante el ejercicio de una Beneficencia ahogada por la dramática coyuntura económica de la ciudad (Krause, 1984). Y, así y todo, las respuestas municipales para el control de la mendicidad siempre se basaron en la misma triada de inocuas medidas: publicación de bandos por parte de la alcaldía anunciando la gravedad del problema, operaciones de recogida de mendigos en las vías públicas y apertura de asilos para proveer de alojamiento y manutención temporal a los más desfavorecidos ${ }^{1}$.

A primera vista, la inauguración de los asilos, costeados por instituciones filantrópicas o por el consistorio, bien podría escenificar el advenimiento de un nuevo tipo de sensibilización con las condiciones de vida de las clases menesterosas en Madrid siguiendo el modelo de otras ciudades europeas (Katz, 2015). Sin embargo, la acción social desarrollada en ellos distó de cumplir con los objetivos inicialmente marcados de combatir la miseria de un sector relevante de la población suprimien-

${ }^{1}$ Véanse los documentos custodiados por el Archivo de Villa de Madrid (AVM) relativos a la represión de la mendicidad en: AVM, Secretaría, Bando del Gobernador Civil de Madrid de 4 de abril de 1881, 5-429-2, AVM, Secretaría, Bando del Sr. Alcalde, marqués de Bogaraya, con fecha 8 de febrero de 1884, con varias disposiciones para las licencias de pedir limosna en las calles y sitios públicos, 6-149-10, AVM, Secretaría, Expediente promovido por decreto de la Alcaldía Presidencia para la recogida de mendigos en la vía pública conforme al bando contra la mendicidad de 5 de abril de 1895, 11-384-61. 
do, de manera paralela, la holganza de quienes anteponían la senda de la limosna a la del trabajo. Lejos de fomentar la previsión social, los asilos solo sirvieron para ejercer un control del espacio urbano en épocas críticas. Su grado de abandono se hizo alarmante a partir de 1900 y las negligencias cometidas por las instituciones que los sostenían facilitaron su transformación en caldo de cultivo para el desarrollo de enfermedades infecciosas.

El presente artículo parte de este marco previo para analizar las características de la primera epidemia de tifus exantemático experimentada por Madrid a partir de finales de abril de 1903 y prolongada, con diferentes intensidades, hasta finales de 1905. En primer lugar, se abordarán las principales reacciones de las autoridades públicas y sanitarias ante la aparición de este problema sanitario. En segundo lugar, se detallarán los primeros compases de la campaña desarrollada por las autoridades políticas y sanitarias para luchar contra la enfermedad. Posteriormente, se analizarán las causas del recrudecimiento de la epidemia a lo largo del primer semestre de 1904. Y finalmente, se hará un balance de sus diferentes brotes en términos etarios y socio-espaciales.

\section{EL NACIMIENTO DE UN PLEITO MÉDICO-SANITARIO}

Corría el 30 de abril de 1903. Los madrileños todavía saboreaban el triunfo republicano en las elecciones legislativas celebradas cuatro días antes, en lo que era un primer botón de muestra de la incipiente crisis del sistema político de la Restauración. Los periódicos abrieron sus ediciones aludiendo a los mítines de los vencedores y al júbilo del vecindario de los barrios bajos del casco antiguo, pero paralelamente comenzaron a dar la voz de alarma sobre el inicio de una nueva epidemia. El Día informaba del elevado número de pacientes ingresados durante las dos semanas anteriores en el Hospital Provincial, atacados por fiebres de entre 39응 y 40․ El Globo advertía del traslado de una importante cantidad de enfermos al Hospital del Niño Jesús y de la incapacidad de las instalaciones sanitarias de la urbe para afrontar eventuales complicaciones en días venideros, lanzando, en adición, las primeras especulaciones sobre el tipo de enfermedad que padecían aquellas personas. Sus síntomas Ilevaron a pensar inicialmente en fiebres gripales, pero ya había otros especialistas que apuntaban a una epidemia de fiebre tifoidea o de tifus exantemático, como se comprueba al analizar las páginas dedicadas al tema en El Imparcial, El País y El Liberal².

El último de esos diarios había hecho un seguimiento lo suficientemente prolijo de lo que estaba ocurriendo en los días previos en el Asilo de Mendigos de la Montaña del Príncipe Pío como para justificar una creciente preocupación por

\footnotetext{
2 El Imparcial, El País, El Liberal, El Día y El Globo, 30 de abril de 1903.
} 
la cuestión sanitaria y por la forma en que la practicaban los agentes del gobierno urbano. Llamaron su atención los rudimentarios convoyes de cuatro camillas que con inusitada frecuencia partían de ese punto para dirigirse al Hospital Provincial, utilizando como guías las calles de Bailén y de Atocha y acompañados por un único guardia municipal. Tampoco pasó por alto las inquietudes que esto generaba entre los vecinos de las calles más cercanas al depósito de indigentes ${ }^{3}$. La primera autoridad sanitaria que reaccionó ante este escenario fue el doctor Enrique Fernández Sanz, médico numerario de la Beneficencia Municipal de Madrid. Había estado presente en el Hospital Provincial analizando los síntomas que ofrecían los nueve enfermos que ingresaron los días 26 y 27 de abril procedentes del mencionado asilo. Todos ellos presentaban fiebre alta (cercana a los 40), un estupor muy acentuado (que derivaba en estado comatoso), erupción cutánea pápulo-eritematosa, signos auscultatorios de bronquitis generalizada y un ligero dolor abdominal ${ }^{4}$. El estado tífico, el exantema, los signos torácicos y la falta de trastornos intestinales de los ingresados le llevaron a pensar en un diagnóstico específico: tifus exantemático.

Durante el siglo anterior, el foco endémico de esta enfermedad fue Irlanda, aunque también pudieron encontrarse casos en las provincias del Báltico, la Silesia superior, Polonia, Bohemia, Italia (Nápoles y sus contornos), Reino Unido y Francia. Este último país había sido invadido en diferentes ocasiones por epidemias tíficas, siendo la más relevante la que importaron las tropas al regreso de la Guerra de Crimea, y contando con algunos focos significativos, aunque no plenamente contrastados, en Toulon, Reims, Nancy, Estrasburgo y París. Dejando a un lado el continente europeo, fue el africano el que había contabilizado el mayor número de brotes, destacando los de Argel (1861 y 1868), Bugia (1862) y Constantina (1863 y 1867) $)^{5}$. Pero ya entre 1900 y 1905, España se convirtió en el tercer país con mayor número de defunciones asociadas a esta enfermedad solo por detrás de Austria e Hungría, si bien la inmensa mayoría de ellas se produjeron en Madrid.

${ }^{3}$ El Liberal, 30 de abril de 1903.

4 Sobre los síntomas del tifus exantemático véase: González Campo, 1904.

5 La incidencia internacional del tifus exantemático en: Wilder, 1911; Quintal, 1996; Hamonet, 1997 y Bechah, Capo, Mege y Raoult, 2008. 
Gráfico 1. Número de fallecidos por tifus exantemático en Europa (1900-1905)

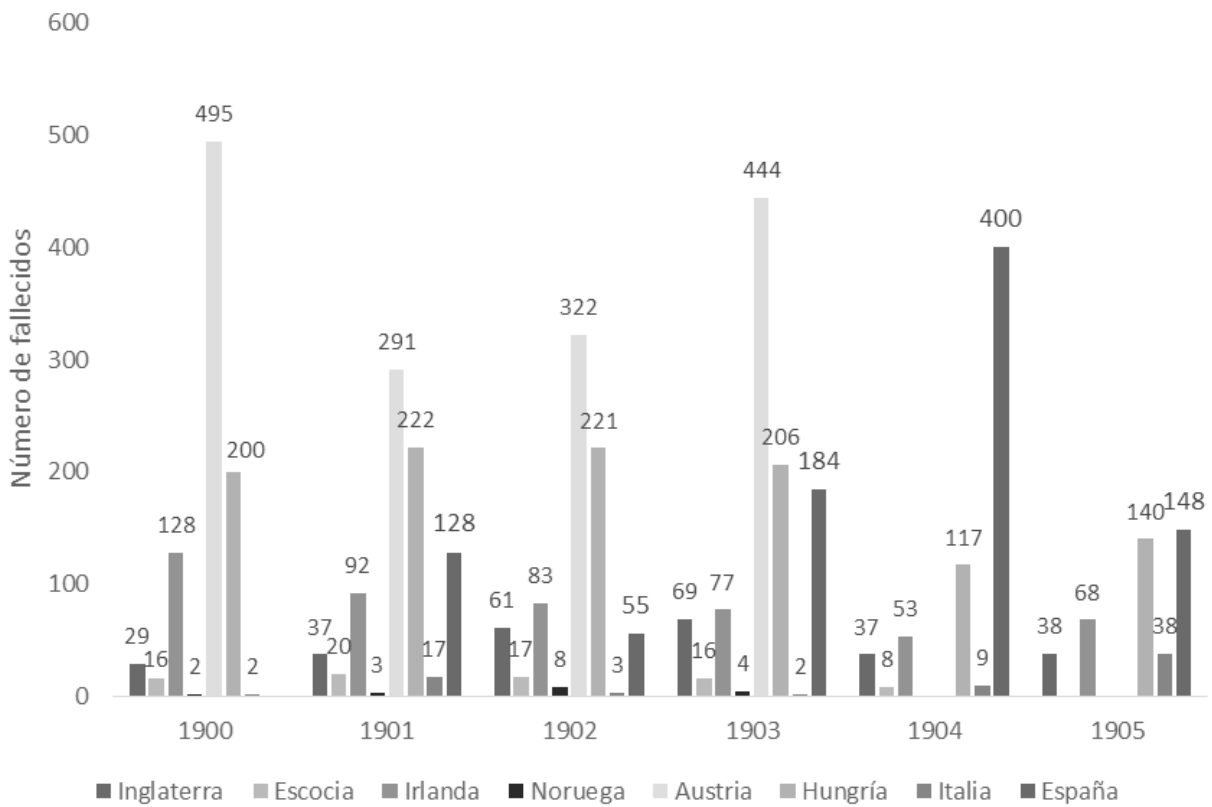

Fuente: Elaboración propia a partir de: HAUSER, Philip (1913), La geografía médica de la Península Ibérica. Vol. 2., Madrid, Imprenta Arias, pág. 288 e INSTITUTO NACIONAL DE ESTADÍSTICA (INE), Movimiento Natural de la Población de España (1900-1905).

La aparición de una epidemia de tifus exantemático en Madrid era, cuanto menos, inesperada. En el discurso pronunciado en la sesión inaugural del Ateneo Médico-Quirúrgico, celebrado medio año después del descubrimiento del brote, el doctor Nicolás María Cirajas, uno de los encargados de la asistencia de los enfermos en el Hospital de Epidemias del Cerro del Pimiento, destacó la sorpresa que causaron las primeras voces de alarma dadas por los médicos que asistieron a los primeros atacados. Escudándose en el carácter inédito de esa enfermedad en España en general y en Madrid en particular, Cirajas justificó la discrepancia de criterios presentada entre las principales autoridades médicas y sanitarias de la ciudad y los equívocos diagnósticos realizados entonces (Cirajas, 1903, p. 21).

Las autoridades gubernamentales no valoraron en su justa medida la carta publicada por el doctor Fernández Sanz en El Liberal ni las recomendaciones que dio para atajar el problema ${ }^{6}$. Quien intervino en primer lugar fue José Sánchez Guerra,

${ }^{6}$ Una de ellas determinaba la colaboración que podían prestar los médicos de los países en los que el tifus exantemático fuera endémico, aprovechando que el XIV Congreso Internacional 
Gobernador Civil de Madrid, que transmitió órdenes al doctor Veranes, subdelegado de medicina del distrito de Palacio, al que pertenecía administrativamente el Asilo de Mendigos de la Montaña del Príncipe Pío, para girar una visita de inspección al mismo. El objetivo era estudiar la enfermedad in situ para ir descartando posibilidades. Veranes adelantó a la prensa que la afección de algunos de los asilados no era el tifus exantemático, sino fiebres gripales sin carácter epidémico. Secundó su postura César Chicote, director del Laboratorio Municipal de Higiene de Madrid, afirmando que la dolencia del tifus exantemático solo podía producirse por la infección del agua del Lozoya consumida en determinadas zonas de la capital, algo no comprobable en el asilo. Finalmente, el doctor Quintana, encargado del cuidado de los enfermos del depósito de mendigos, redactó una nota en la línea negacionista de las anteriores declaraciones que recogía las disposiciones tomadas por la institución para el tratamiento de los afectados:

La enfermedad que padecen los asilados voluntarios es de grippe, de forma gastro-intestinal, y dicha enfermedad no ha ofrecido gravedad ni por su duración, que no ha excedido de doce días, ni por su forma, sin que se haya presentado ningún síntoma grave hasta su terminación y sin que tampoco haya ocurrido defunción alguna. En la actualidad existen en el depósito veinte individuos en convalecencia. Los medios empleados durante esta enfermedad y en el momento presente han sido: aislamiento absoluto, desinfección por los medios que aconseja la ciencia y alimentación y medicación reparadora ${ }^{7}$.

Como señaló Cirajas, las autoridades médicas y sanitarias que apostaron por una forma de gripe tenían, al menos inicialmente, ciertas razones para ello. Entre éstas destacaban la benignidad que presentaron los primeros casos de tifus exantemático y la emisión de juicios clínicos basados en síntomas prodrómicos «semejantes y hasta pudiera decirse que iguales a los del tifus exantemático» (Cirajas, 1903, p. 21). Algo parecido podría afirmarse de quienes consideraron que la enfermedad que padecían los asilados era una forma clínica de sarampión, atendiendo principalmente a un exantema que "es tan parecido al del sarampión, sobre todo en aquellos casos leves de tifus, que seguramente hubiera pasado sin discusión por un caso de esta enfermedad un caso de tifus presentado esporádicamente» (Cirajas, 1903 , p. 22). En este sentido, debía recurrirse al estudio de la fiebre, pues el descenso de la temperatura en el sarampión se producía durante el período prodrómico, algo que no acontecía en el tifus exantemático. Asimismo, la fiebre desaparecía en el sarampión cuando la erupción había alcanzado su apogeo y el estupor ofrecido

de Medicina se estaba celebrando esa semana en Madrid. En: El Liberal, 30 de abril de 1903.

7 El Imparcial, 1 de mayo de 1903. 
por los atacados de esta enfermedad no era tan acentuado como en la segunda enfermedad.

Tampoco faltaron quienes pensaron que Madrid estaba viviendo, en realidad, una epidemia de fiebre tifoidea ${ }^{8}$. El estado de decaimiento de los enfermos llevaba a valorar esta posibilidad, sin embargo remota si se atiende a los diferenciales que presentaba con respecto al tifus exantemático en cuatro apartados (Del Valle, 1903). Primero en la fiebre, definida por una elevación abrupta en el caso del tifus exantemático tras los primeros escalofríos; alta y sostenida, si bien con ligeras oscilaciones durante un cierto período de tiempo; y sometida finalmente a un descenso también rápido, aunque sin alterar el carácter crítico de la enfermedad. En la fiebre tifoidea, la temperatura ascendía de forma escalonada, necesitando cierto tiempo para llegar al segundo estadio y quedando finalmente asociada a un descenso por lisis. En segundo lugar, en la manera de conducirse el pulso, estando en el caso del tifus exantemático directamente relacionado con la temperatura y caracterizándose en la fiebre tifoidea por una marcada lentitud y la falta de correspondencia con la temperatura determinada por la curva térmica. En tercer lugar, en el exantema. Al igual que ocurría en el tifus exantemático, la fiebre tifoidea venía acompañada por la aparición de manchas en el cuerpo del atacado que se producían de manera más tardía que en la primera enfermedad, en menor cantidad y casi siempre localizadas con la pared abdominal. Y en último lugar, en el conjunto de síntomas del aparato digestivo. Siguiendo a Cirajas, en la fiebre tifoidea existía un timpanismo generalizado y un gorgoteo en la región íleo-cecal, acompañado por un dolor intenso. También solía presentarse una diarrea generalizada solo esporádicamente detectada en el tifus exantemático (Cirajas, 1903, p. 75).

No hubo inicialmente un criterio fijo con respecto a una verdad incómoda. Entre los diferentes doctores que estaban sometiendo casos a su observación (entre ellos, Simón Hergueta, Manuel Alonso Sañudo, Juan Madinaveitia y Francisco Huertas), solo Ricardo Pérez Valdés, encargado del cuidado de los enfermos procedentes del asilo en una de las salas habilitadas en el Hospital Provincial, tuvo claro el diagnóstico del tifus exantemático. Su dictamen sirvió para que el Cuerpo de la Beneficencia Provincial de Madrid emitiera un juicio provisional sobre el caso, confirmando un principio de epidemia que vino además corroborado por el contagio que se había producido en uno de los enfermeros de las salas del recinto hospitalario; por la autopsia practicada sobre uno de los atacados e incluso por la visita dirigida por el doctor Albert Robin, miembro de la Real Academia de Medicina de París, a los enfermos del hospital, emitiendo idéntico diagnóstico ${ }^{9}$.

Sin embargo, fueron los análisis del doctor Antonio Mendoza, jefe del Laboratorio Provincial de Madrid, los que permitieron una comprobación más precisa.

8 El Imparcial, 2 de mayo de 1903.

9 La Época, 3 de mayo de 1903. 
Practicó hasta veintiún ensayos de serodiagnóstico de Widal y Courmont con la sangre de otros tantos enfermos invadidos, en presencia de cultivo puro de veinticuatro horas del bacilo de Eberth, y en ningún caso se dieron características arquetípicas de la fiebre tifoidea ${ }^{10}$. Por el contrario, en los exámenes microscópicos realizados con los esputos de ciertos atacados se acusó la existencia generalizada de un tipo de diplococcus que podía asociarse con el indicado en el tifus exantemático. Tampoco se halló en los casos analizados el bacilo de la gripe y en todos hubo una gran cantidad de vírgulas de Miller, a causa de las fuliginosidades bucales de los pacientes. Al margen de los datos obtenidos con los análisis de laboratorio, Mendoza realizó una inspección pormenorizada de los enfermos con la que se observaron evidentes características del tifus exantemático: la extensión y persistencia del exantema, el estupor y el subdelirio, la incapacidad de movimiento y el aspecto vultuoso de la facies. Estas observaciones culminaban con otras relativas a la gran contagiosidad de la enfermedad:

No son el aire y el agua los vectores del germen, sino el contacto inmediato con los enfermos, con sus ropas y con las de uso de cama, en las que se alojan las descamaciones de la piel. Hambre, miseria, hacinamiento y falta de higiene y aseo son nada más concausas que predisponen al contagio y a la formación de focos. Por consiguiente, las medidas profilácticas han de ser severas hasta la exageración, rápidas en su desarrollo, eficientes en sus resultados y sabiamente dispuestas en su aplicación; de lo contrario, nos expondremos a que la epidemia tome carta de naturaleza entre nosotros ${ }^{11}$.

Los análisis del doctor Mendoza evidenciaron el error que las autoridades cometieron inicialmente instalando a los enfermos en un hospital que no era epidémico (el Provincial) y que se encontraría expuesto a un contagio más o menos intenso en función de cuáles fueran las medidas profilácticas asumidas. Ante estas noticias, el presidente de la Diputación Provincial, Justino Bernad, decidió instalar en el recinto una sala destinada exclusivamente a los enfermos citados, con el objetivo de que estuvieran completamente aislados de los restantes no atacados por la epidemia. Paralelamente, el alcalde de Madrid, marqués de Portago, dispuso la inmediata habilitación de dos pabellones para cuarenta personas en el Hospital Epidémico del Cerro del Pimiento, que se encargaría de atender al grueso de los afectados por la enfermedad con todo el material necesario para la asistencia facultativa ${ }^{12}$, y de veinticuatro camas en el Hospital de San Juan de Dios, instaladas en un pabellón

${ }^{10}$ El Día, 2 de mayo de 1903.

${ }^{11}$ El Liberal, 5 de mayo de 1903.

12 La Época, 2 de mayo de 1903. 
independiente del resto del edificio ${ }^{13}$. Asimismo, se transmitieron órdenes al Laboratorio Municipal de Higiene de Madrid para proceder a la inmediata desinfección de las viviendas que ofrecieran pocas garantías de higiene y salubridad y que registraran casos sospechosos de contagios ${ }^{14}$.

Los inicios de la epidemia ponían de nuevo de relieve el creciente peso de la miseria en Madrid y sus dramáticas consecuencias higiénico-sanitarias. Pero sobre todo, este escenario suponía un reto de considerables dimensiones para unas instituciones administrativas y políticas notablemente cuestionadas durante los años anteriores. En medio de este complejo contexto, comenzaba una campaña sanitaria contra una enfermedad inédita en la ciudad y cuyo agente patógeno se desconocía por completo.

\section{LAZONA CERO DELTIFUS EXANTEMÁTICO EN MADRIDY LA ORGANIZACIÓN INICIAL DE LA CAMPAÑA SANITARIA}

La caracterización del tifus exantemático como una enfermedad altamente contagiosa imponía la necesidad de unas medidas preventivas que fueron publicándose inmediatamente después de la confirmación de un principio de epidemia ${ }^{15}$. Las autoridades sanitarias entendían que ésta podía sofocarse completamente en sus inicios si se recurría al aislamiento radical de los atacados, incluyéndose entre ellos también a los médicos y enfermeras que les habían tratado en el Hospital Provincial y dejando de lado las acostumbradas desinfecciones y las estufas que podían utilizarse en el asilo para sustituirlas por un verdadero agente microbicida como el fuego. En este sentido, se exigía quemar las ropas de los afectados y destruir sus deyecciones, los enseres y objetos de los que hubieran hecho uso y las instalaciones del asilo en que se había incubado la enfermedad. Todavía en aquel momento se pensaba que las probabilidades de que la dolencia se propagara a otros puntos de la ciudad eran remotas, pero las circunstancias no eran halagüeñas y llevaban a valorar la inmediata eliminación de cuanto pudiera representar un agente transmisor de los exantemas ${ }^{16}$.

De esta manera, los primeros pasos en el control de la epidemia se dirigieron a la consecución del inmediato cierre y posterior incineración del Asilo de la Montaña del Príncipe Pío. Existía la certeza de que el hacinamiento en lugares oscuros, húmedos y mal ventilados, la suciedad, la miseria fisiológica y la ausencia de unas normas rudimentarias de higiene eran condiciones individuales y colectivas que encajaban

\footnotetext{
13 La Época, 4 de mayo de 1903.

${ }^{14}$ El Globo, 2 de mayo de 1903.

${ }^{15}$ Heraldo de Madrid, 2 de mayo de 1903.

${ }^{16}$ La Época, 4 de mayo de 1903.
} 
con el nacimiento y posterior desarrollo de la enfermedad (Rísquez, 1903, pp. 267269). En este sentido, resultaba evidente que el mencionado depósito de indigentes reunía estos requisitos ${ }^{17}$. La prensa transmitió a la opinión pública todo lujo de detalles sobre sus dependencias, definiendo el recinto como un inmundo y destartalado caserón formado por dos cuerpos de edificios levantados alrededor de un patio hediondo con apariencias de corral. Ese hotel de la miseria, como se bautizó desde El Liberal, simbolizaba los estertores de la malhadada Corte de los Milagros decimonónica. Las visitas de inspección practicadas por los redactores de ese diario mostraron un edificio en obras, carente de puertas, ventanas e incluso de algunas de las cañerías de los cuartos de aseo de los acogidos. La sala destinada a los hombres, que en estos momentos hacía las veces de improvisada enfermería, presentaba camas que no eran más que «viejas tarimas de tablas carcomidas y sucias» y una estufa de hierro viejo sin cubierta con la que inútilmente se intentaba caldear la estancia.

Resulta particularmente interesante el perfil de quienes allí se congregaban cada noche. El depósito estaba plagado de «golfos, pordioseros y ladronzuelos precoces de la clase de quincenarios», de todas las variedades del buscavidas que vivían allí «hacinadas, en fea promiscuidad, en montón maloliente, como pingajos de trapero o piltrafas de carne agusanada y podrida ${ }^{18}$. Todos ellos eran víctimas del entramado benéfico y asistencial que notorios matices de moralización y punición se fue tejiendo en el Madrid de finales del ochocientos sobre el problema de la mendicidad. Los asilos nocturnos, como el de la Montaña del Príncipe Pío, funcionaban, de facto, espacios en los que indistintamente coincidían los que anteriormente se categorizaban como pobres válidos, que ingresaban por su situación de desempleo, y pobres inválidos, que hacían de la mendicidad y la limosna carrera profesional ${ }^{19}$.

El Asilo de la Montaña del Príncipe Pío estaba regentado por la Asociación Matritense de Caridad, sociedad benéfica creada en 1899 que contaba con el apoyo del consistorio y que se proponía contribuir a la erradicación de la mendicidad en Madrid ${ }^{20}$ nació de la voluntad municipal por inducir a la población marginal a recuperar una situación social ordinaria, utilizando la actividad laboral como único medio de reeducación. No en vano, se trataba de un refugio provisional, que supeditaba la estancia de los acogidos a la obtención de bonos y papeletas para trabajar en algún

17 El Siglo Médico, no 2.581, 31 de mayo de 1903, pp. 343-344.

18 El Liberal, 4 de mayo de 1903.

19 Esta distinción puede contemplarse teóricamente en: Damon, 2007.

20 Durante su primer año de existencia, la Asociación Matritense de Caridad retiró más de 1.500 mendigos de las calles de Madrid, asilando a unos, concediendo pensiones a otros y conduciendo a los restantes a sus pueblos de origen. La mayor parte de esos mendigos eran enviados al depósito de la Montaña del Príncipe Pío abierto en 1897, distribuyéndose los demás entre el Asilo de Santa Cristina, los Asilos del Pardo y otros pertenecientes a la beneficencia particular. En: La Época, 7 de agosto de 1900. 
tajo. En el recinto no se admitía a ningún mendigo que no llegara acompañado por un agente de la autoridad, quedando inmediatamente registrado y abriéndose un historial en el que figuraban el sitio y manera en el que fue encontrado y llevado al depósito, información sobre su filiación recabada por el mencionado agente y dictamen del médico del asilo en el momento de la entrada.

Sobre el papel, los acogidos debían recibir una dieta alimenticia consistente en un plato de menestra o guisado y 200 gramos de pan por la mañana y otra comida idéntica por la tarde a las horas que se fijaran según la estación del año. Todas las comidas se pedían por raciones pagadas al contado por el conserje del recinto por medio de bonos adquiridos directamente por la asociación. No se permitía, bajo pretexto alguno, la salida del depósito de los ingresados en el mismo, salvo en aquellos casos en que fueran reclamados por familiares o personas que quisieran hacerse cargo de ellos. No obstante, los acogidos podían solicitar la salida por decisión propia adquiriendo el compromiso de no mendigar, bajo apercibimiento de que si fuesen nuevamente encontrados en dicha actitud serían considerados como reincidentes, quedando en este caso detenidos y siendo entregados a las respectivas Delegaciones de Vigilancia de la ciudad (Asociación Matritense de Caridad, 1899).

Los reglamentos del Asilo de Mendigos de la Montaña del Príncipe Pío especificaban una serie de normativas para su organización interna. El conserje del local debía observar el más perfecto orden en patios y dormitorios, procurando a través de los oportunos medios de persuasión que los mendigos adoptaran costumbres de aseo y limpieza, a cuyo efecto se ofrecía incluso como estímulo (fundamentalmente a los golfos), monedas de cinco o diez céntimos y raciones extraordinarias de comida. También debía existir una separación absoluta de hombres, niños y mujeres y niñas para evitar la promiscuidad y la mezcolanza generacional y sexual de los internos.

Sin embargo, la eficacia de todas estas disposiciones fue nula por factores relacionados con las escasas dotaciones presupuestarias destinadas por el consistorio a los asilos nocturnos. Las condiciones en las que quedaron los atacados en la enfermería del depósito de mendigos de la Montaña del Príncipe Pío lo demuestran de manera palmaria. En los primeros momentos de la epidemia, su alimentación consistía en un vaso de té, leche o coñac en el desayuno; una comida compuesta de media libreta de pan, un plato de cocido y otro de carne y tocino y una cena formada por otra media libreta de pan y un plato principal que variaba entre lentejas, judías o arroz con patatas. Según la información publicada por El Liberal, los atacados yacían tendidos en camastros sin jergones, sin almohadas y arropados con «mantas de dudosa limpieza» ${ }^{21}$.

${ }^{21}$ El Liberal, 4 de mayo de 1903. 
Imágenes 1 y 2. Comedor y dormitorios del Asilo de Mendigos de la Montaña del Príncipe Pío

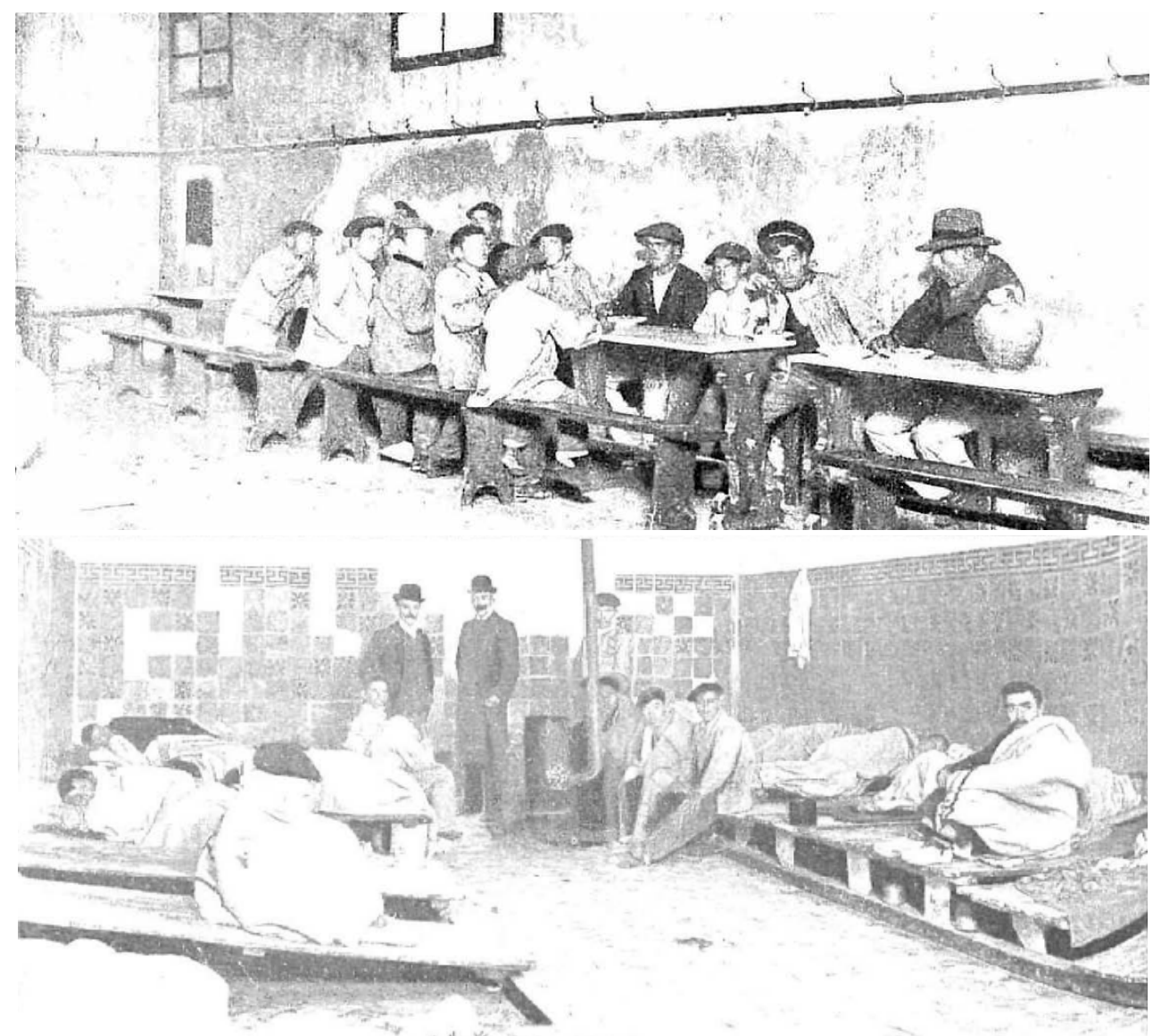

Fuente: Nuevo Mundo, 6 de mayo de 1903.

Los mecanismos de control en los registros distaron de ser rigurosos. No en vano, el tifus exantemático iniciado en el asilo había sido importado a Madrid durante un período de tiempo relativamente largo que se remontaba a 1902. En este año se habían registrado 74 muertes causadas por la enfermedad en toda España, siendo las provincias con mayor protagonismo en términos de representatividad numérica Almería (treinta y siete defunciones), Murcia (ocho), Lérida (seis) y Valencia (cinco), seguidas por otras como Albacete y Sevilla (con tres casos registrados), Córdoba, Málaga y Zaragoza (dos casos) y Cáceres, Cádiz, A Coruña, Lugo, Orense y Palencia (un caso) ${ }^{22}$. Cabía la posibilidad de que la enfermedad hubiera llegado a la

22 Información extraída de los resúmenes estadísticos de defunciones ocurridos en las capitales de provincia españolas en 1902 (Dirección General de Sanidad). En: Gaceta de Madrid, no 133,13 de mayo de 1903, pp. 560-561. 
Península por la franja levantina, conectada con focos endémicos de larga tradición por vía marítima. Otras hipótesis apuntaban a que el germen había sido difundido por un grupo de húngaros dedicados a implorar la caridad pública en las calles de Madrid, ignorándose, sin embargo, el camino seguido hasta su llegada a la capital $^{23}$. Pero lo que todo esto mostraba era, en definitiva, la enorme debilidad de la campaña sanitaria seguida por el Ayuntamiento de Madrid y por las instituciones benéficas privadas en el ingreso de acogidos en los asilos.

La destrucción del Asilo de Mendigos de la Montaña del Príncipe Pío se produjo finalmente en la madrugada del 5 de mayo de 1903. Hasta ese día permanecieron encerrados en el recinto 150 acogidos, independientemente de si ya estaban atacados o no. La decisión se tomó al hilo de una reunión celebrada un día antes en el ministerio de la Gobernación entre el director general de Sanidad, Carlos María de Cortezo; el alcalde de Madrid, el presidente de la Diputación Provincial y el Gobernador Civil. A buen seguro que a juicio de los que allí concurrieron era preferible cerrar a cal y canto el refugio aun facilitando el contagio de los mendigos que todavía no habían sido atacados que liberarles y arriesgarse a una rápida difusión de la enfermedad ${ }^{24}$. En este encuentro de autoridades se determinó también dejar la campaña sanitaria en manos de Cortezo y regularizar el control de la epidemia tomando como base de operaciones el Hospital Epidémico del Cerro del Pimiento ${ }^{25}$. Este quedó a disposición del Cuerpo de Beneficencia Provincial, comprometiéndose el consistorio a correr con los gastos que originara. El marqués de Portago se encargó de dirigir una primera visita de inspección al mencionado hospital para garantizar el riguroso cumplimiento de las preceptivas normas de seguridad e higiene en el desplazamiento de enfermos y en su posterior cuidado ${ }^{26}$. Paralelamente, se tomó la decisión de trasladar a los asilados que no presentaban la enfermedad (pero también a quienes la habían incubado sin exteriorizarla de manera sintomática) al Asilo del Sur, situado en la calle de Méndez Álvaro ${ }^{27}$.

Una nueva reunión celebrada el 6 de mayo con la participación de las anteriores autoridades sirvió para tratar sobre los recursos necesarios para los servicios a

${ }^{23}$ Sobre el origen del tifus exantemático, véase: Cirajas, 1903, pp. 27 y 28.

${ }^{24}$ El Siglo Médico, № 2.581, 31 de mayo de 1903.

${ }^{25}$ La posterior R.O. del ministerio de la Gobernación publicada en la Gaceta de Madrid del 7 de mayo nombró a Cortezo delegado especial del mismo, a fin de que adoptara las medidas necesarias para impedir la propagación de la epidemia. Su protagonismo en el control de la epidemia es analizado en: Schoendorff, 1988 y Rodríguez Ocaña, 2007.

${ }^{26}$ Heraldo de Madrid y El Globo, 5 de mayo de 1903.

27 Este traslado no dejaba de ser conflictivo, toda vez que el contrato sobre el Asilo del Sur, instalado en una casa particular, estaba próximo a vencer en un plazo de dos semanas. Su propietario declaró además a la prensa su propósito de dar por concluido dicho contrato a su vencimiento, por el temor de que allí se declarase otro foco epidémico de tifus. En: Heraldo de Madrid, 6 de mayo de 1903. 
desarrollar en este último recinto. La campaña sanitaria parecía contar desde un primer momento con el apoyo económico del Ministerio de la Gobernación (que ponía a disposición de la Dirección General de Sanidad un servicio de vigilancia) y con el envío de camas y servicios de carpintería y vidriería por parte de la Diputación Provincial, fundamentales para arreglar los desperfectos del establecimiento ${ }^{28}$. Por su parte, la alcaldía ofreció a la Dirección General de Sanidad recursos para costear el material necesario en los primeros momentos de funcionamiento del recinto hospitalario en el control de la epidemia ${ }^{29}$. A partir de este momento, el servicio médico del hospital quedó bajo la organización del doctor Santiago de los Albitos, decano de la Beneficencia Municipal, con la prestación de cinco médicos del cuerpo (tres de visita y dos de guardia). El servicio de farmacia y enfermería sería facilitado por el Hospital de la Princesa, el de practicantes encomendado a alumnos internos de la Facultad de Medicina y el de desinfección al Laboratorio Municipal de Higiene ${ }^{30}$.

Sin embargo, los plausibles planes organizativos para el control de la epidemia estuvieron lejos de cumplirse ${ }^{31}$. Se reaccionó tarde, ya que para aquel entonces se habían cometido negligencias significativas en el tratamiento de los enfermos trasladados desde el Asilo de la Montaña al Hospital Provincial. El médico socialista José Verdes Montenegro fue el primero en denunciar las deficiencias de este recinto $^{32}$. A su juicio, era un hecho indiscutible que la epidemia del tifus exantemático se había incubado en el hospital, favoreciendo el contagio de pacientes aquejados de enfermedades generales, médicos y enfermeras. Las causas tenían que ver con la ausencia de un departamento de observación y aislamiento en el que se recluyese, desde un principio, a individuos sospechosos de padecer cualquier enfermedad contagiosa. El análisis detallado de los libros de filiación de hombres y mujeres del Hospital Provincial confirma que los atacados procedentes del Asilo de la Montaña fueron ubicados en diferentes salas hasta procederse a su aislamiento, la mayoría de enfermedades comunes (salas 16, 28, 37 y 38 hasta su definitiva colocación en la sala 41$)^{33}$.

Pero además de todo ello, existían otros problemas a resolver en el Hospital Provincial relacionados con la organización de sus servicios. El desconcierto y la confusión generada por el tifus exantemático son fenómenos perfectamente detectables si valoramos cómo algunos cadáveres llegaron a permanecer hasta treinta y cuatro horas en el depósito del recinto, sin practicarse las autopsias con la urgencia

${ }^{28}$ El Imparcial, 7 de mayo de 1903 y La Época, 18 de junio de 1903.

${ }^{29}$ El Globo, 8 de mayo de 1903.

${ }^{30}$ Heraldo de Madrid y El Imparcial, 6 de mayo de 1903.

31 El Globo, 7 de mayo de 1903.

32 El Imparcial, 7 de mayo de 1903.

33 Archivo Regional de la Comunidad de Madrid (ARCM), Libros de filiaciones del Hospital Provincial de Madrid (abril-mayo de 1903), sig. 0900536/001 y 002. 
que las circunstancias requerían. A esto se sumaba el hecho de que tanto el depósito de cadáveres como la sala de autopsia carecían de la cantidad de agua necesaria para una eficaz limpieza. Y además, era necesario emprender una actualización del obsoleto servicio de desinfección y una educación más especializada para los enfermeros a fin de transmitirles los mecanismos de contagio de las enfermedades:

Los médicos de guardia del Hospital, jóvenes todos y por lo tanto en pleno período de entusiasmo por la profesión, podría realizar una misión altísima enseñando al personal subalterno los riesgos del trato de los enfermos y el modo de evitarlos. Seguros de que acogerán la idea con simpatía y de que más de una vez habrán pensado lo conveniente de esta enseñanza, deseamos sencillamente animarlos a emprender esta obra de humanidad y de higiene ${ }^{34}$.

Por otro lado, es importante advertir que nada más emitirse las órdenes para la quema del Asilo de la Montaña se acordó el traslado de los enfermos pobres que lo ocupaban a los pabellones del Hospital del Cerro del Pimiento en condiciones que distaron de ser las apropiadas, utilizándose en algunos casos camillas y carros pero recurriéndose en otros al traslado a pie. El acomodamiento de los asilados tampoco fue el idóneo, pues el recinto no contaba con las camas necesarias ni con ropas suficientes para su vestimenta ${ }^{35}$. Las Hermanas de la Caridad que se encargaron de recibirles y cuidarles tampoco pudieron proporcionar alimentos en la medida estimada y se vieron obligadas a recurrir a las dádivas entregadas por el vecindario en forma de pucheros de caldo. $Y$ tampoco deben pasarse por alto las enormes deficiencias que presentaba el Asilo del Sur para la recepción de los asilados no enfermos. Estos quedaron asentados en dos salones entarimados alumbrados por mecheros de gas en unas dramáticas condiciones de hacinamiento. Su traslado al mencionado depósito fue un error imperdonable en los inicios de la campaña sanitaria. Pese a que no habían presentado síntoma alguno de la enfermedad hasta su inserción en dicho recinto, se les podía presuponer, y con sobradas razones, contaminados. Esta hipótesis parece confirmarse si se analizan los primeros casos de atacados procedentes de este depósito de mendigos registrados en el Hospital del Cerro del Pimiento y reproducidos con detalle en la prensa ${ }^{36}$.

${ }^{34}$ Verdes Montenegro, José: «Enseñanzas. El Hospital Provincial», en: El Imparcial, 7 de mayo de 1903.

${ }^{35}$ Estas carencias trataron de ser posteriormente subsanadas con la colaboración del Instituto de Alfonso XII, que entregó al hospital de epidemias, por orden del doctor Cortezo, una importante cantidad de prendas de vestir y una buena provisión de objetos y materiales para evitar gastos adicionales a este establecimiento. Asimismo, Cortezo decidió abrir una suscripción pública con destino a los gastos que la estancia de los enfermos de tifus exantemático originase en el hospital. En: Diario Oficial de Avisos de Madrid, 13 de mayo de 1903.

${ }^{36}$ El Globo, 7 al 11 de mayo de 1903 y El País, 11 de mayo de 1903. 
Imágenes 3 y 4. Pabellones y dormitorios del Hospital de Epidemias del Cerro del Pimiento
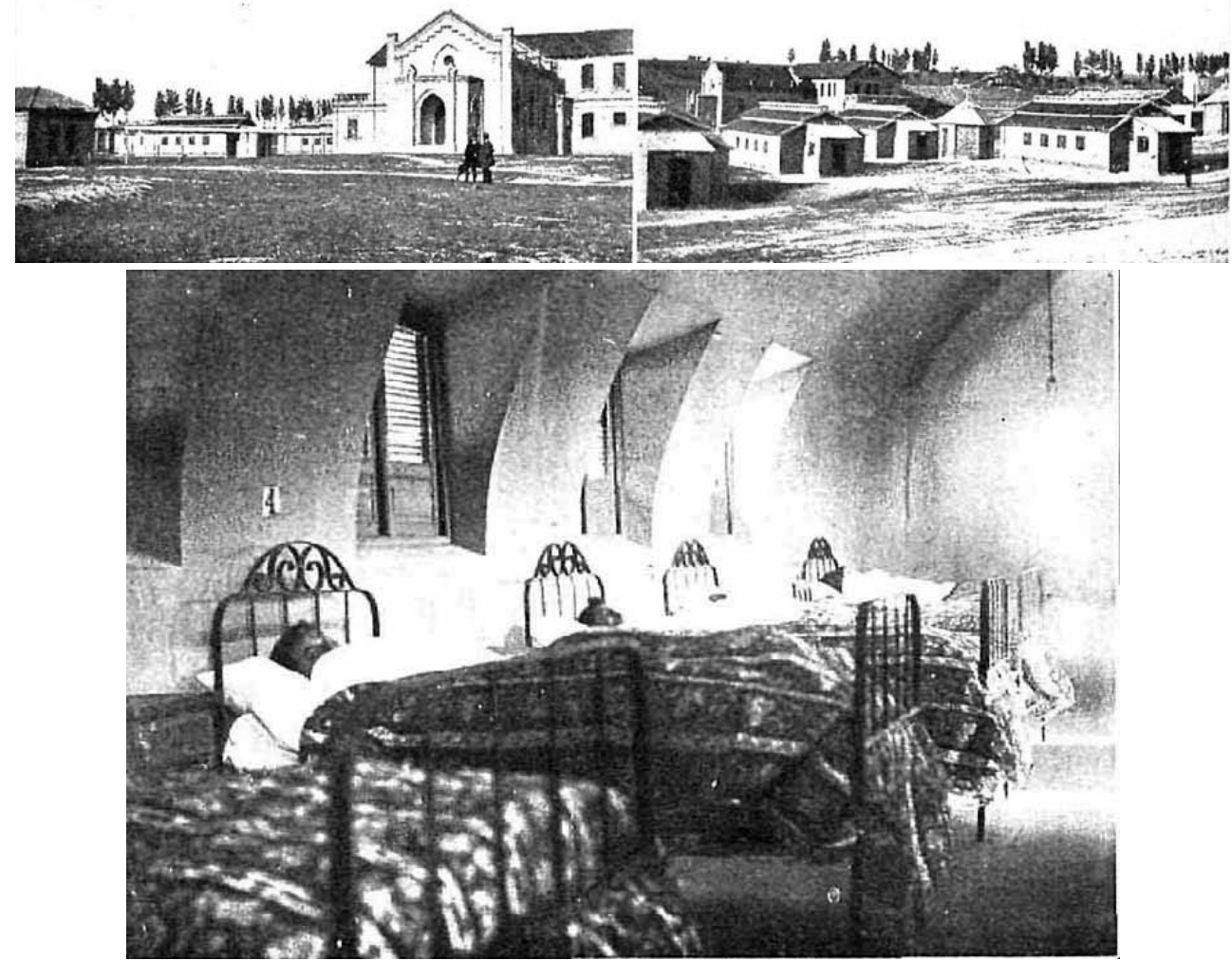

Fuente: Nuevo Mundo, 10 de mayo de 1903.

Pese a todo, a mediados de mayo de 1903 se hablaba abiertamente de un cierto control de la epidemia gracias a las disposiciones gubernativas, provinciales y municipales y a la eficacia de los trabajos emprendidos por Cortezo. Habían comenzado a ser dados de alta los enfermos inicialmente trasladados al Hospital Provincial y los del Hospital del Cerro del Pimiento presentaban síntomas de mejoría ${ }^{37}$. Sin embargo, las esperanzas resultaron efímeras. La epidemia no tardó en experimentar su primer brote significativo con los nuevos casos presentados tanto en el Hospital Provincial, como en el Asilo del Sur y en la Casa de Socorro del Distrito de Palacio, al que había pertenecido administrativamente hablando el depósito de mendigos de la Montaña del Príncipe Pío. Este último punto no debe ser obviado. De hecho certifica como, a pesar de la incineración del asilo, el foco de infección permaneció en lugares anexos al mismo durante un cierto tiempo.

37 Sá del Rey, Enrique: «El tifus en Madrid», en: Nuevo Mundo, 13 de mayo de 1903. 
No fueron pocos los asilados que quedaron libres y que se mantuvieron en los alrededores del Cuartel de la Montaña, en los desmontes de la Cárcel Modelo y en las inmediaciones del mal Ilamado Palacio de Cristal, compuesto por una serie de casuchas en torno a esta zona que servía de nido para buena parte de la golfería de Madrid, como magistralmente retrataron Pío Baroja en La Busca (1968) y Bernaldo de Quirós y Llanas de Aguilaniedo en La Mala Vida en Madrid (1998). A partir de este momento, la lucha iniciada por las autoridades para combatir la epidemia se tornaría completamente estéril.

\section{LA COMPLEJA SUPERACIÓN DEL PRIMER BROTE EPIDÉMICO}

El 20 de mayo de 1903, el doctor Cortezo publicó el primer parte oficial de la evolución de la epidemia de tifus exantemático en Madrid ${ }^{38}$. Bajo su punto de vista, sus embates habían disminuido en gravedad y la aparente expansión de la que se había hecho eco la opinión pública tenía que ver con la mayor rigurosidad con la que los médicos municipales y particulares comunicaban todos los casos atendidos en Madrid. El Hospital del Cerro del Pimiento era ya el único en el que se admitían a tíficos y sospechosos de serlo, con 75 enfermos en sus pabellones. En el Hospital Provincial se registraban entonces siete casos aislados en una sala especial, siendo totalmente inexacto que la enfermedad se hubiera difundido a otras dependencias y habiéndose vaciado, además, los pozos negros del establecimiento, lo que dio lugar a una ostensible mejora de sus condiciones higiénicosanitarias. En cuanto a la propagación de la enfermedad, la perfecta disposición y organización de los servicios desempeñados por el Laboratorio Municipal de Higiene garantizaba una inmediata respuesta a cualquier denuncia vecinal de un posible nuevo foco de tifus exantemático, acudiéndose al lugar indicado con las correspondientes estufas de desinfección y procurando en todo momento el traslado del atacado y el aislamiento de sus familiares y personas más cercanas. Finalmente, a juicio del médico era inexacta la información que la prensa había difundido sobre las condiciones del Asilo del Sur, recientemente desocupado sin que en el momento de esa operación se registraran causas suficientes para retener a los allí acogidos.

¿Cuánto había de cierto en las declaraciones de Cortezo? Ciertamente, la información publicada por El País y por El Liberal ese mismo día contradecía algunas de sus aseveraciones. No en vano, se estaban comenzando a registrar casos de tifus exantemático en las barriadas extremas de Madrid, en calles como las de Galileo, Castilla, Artistas, Toledo, Embajadores, Ronda de Segovia e incluso en Puente de Vallecas. Los enfermos llegaban incluso de ciertos puntos del barrio de Cuatro Ca-

\footnotetext{
${ }^{38}$ La Época, 21 de mayo de 1903.
} 
minos, de Tetuán de las Victorias y de la zona de las Injurias, en el corazón de los barrios bajos de la ciudad. Parecía, además, que el traslado de enfermos al Cerro de Pimiento solo había contribuido a difundir el mal a otro punto sin encontrarse previamente un remedio eficaz ${ }^{39}$. Muchas de las denuncias vertidas por la prensa aludían a la libre circulación de antiguos huéspedes del incendiado Asilo de la Montaña por las calles de Madrid, a los que se habían unido los recientemente desahuciados del Asilo del Sur, para quienes no había esperanzas de encontrar nuevo acomodo por la escasez de recursos económicos que el consistorio y la Asociación Matritense de Caridad manifestaban a la hora de arrendar nuevos inmuebles para sus fines benéfico-asistenciales. En estas condiciones, se esperaba que la amenaza de la epidemia se intensificara en los meses de verano y que la ciudad se viera entonces desbordada ante aquella ${ }^{40}$.

Pronto se verificaron algunos de los peores presagios. El desconcierto que cundía entre los médicos era cada vez más notorio. Ante la creciente llegada de enfermos manifestaban claras inseguridades en sus diagnósticos, discutiendo cuáles de ellos eran tíficos y cuáles no, de ahí que tendieran a clasificarlos en "ciertos, dudosos y enfermos de otras clases de afecciones» ${ }^{41}$. Paralelamente, el número de atacados existente en el Hospital del Cerro del Pimiento aumentó progresivamente hasta superar el centenar al cabo de unos pocos días, lo que hizo cundir la preocupación de no poder responder a un agravamiento de la situación teniendo en cuenta su exiguo número de camas.

Era cierto que el Hospital del Cerro del Pimiento, a medio camino entre los Depósitos del Canal de Lozoya y la Moncloa, ocupaba una extensión de terreno lo suficientemente amplia como para cumplir con el objetivo que se le presuponía y con aparentes condiciones proclives para favorecer la ventilación y el aislamiento evitando la difusión de enfermedades contagiosas. Algunas disposiciones con respecto a la organización del recinto habían sido aplaudidas por la opinión pública, como la construcción de una valla de madera a su alrededor para evitar posibles fugas de enfermos y asilados o las órdenes transmitidas por su administrador, José Gómez Galíndez, para enviar a los mendigos sanos instalados en los pabellones a sus pueblos de procedencia ${ }^{42}$. Sin embargo, el estudio pormenorizado del hospital revela deficiencias difíciles de obviar.

El agua, elemento clave para la terapéutica e higiene de los atacados, escaseaba hasta el punto de que los baños y algunas operaciones de limpieza básicas tenían que ser realizadas mediante la utilización de cubas traídas por operarios del consistorio. Las salas estaban iluminadas por las noches con un alumbrado con-

39 El Liberal, 21 de mayo de 1903.

40 El País, 21 de mayo de 1903.

${ }^{41}$ El Imparcial, 24 de mayo de 1903.

42 El País, 24 a 26 de mayo de 1903. 
seguido a partir del empleo de quinqués de petróleos, generando una atmósfera mefítica junto con las emanaciones de los enfermos. Las características del resto de dependencias tampoco eran halagüeñas. El hospital contaba con una cocina de muy reducidas dimensiones y los pabellones dispuestos para los tíficos denotaban unas clamorosas circunstancias de hacinamiento ${ }^{43}$.

A todo ello se añadía la perniciosa situación que presentó el personal facultativo del hospital a medida que avanzó la epidemia. En las primeras semanas de junio de 1903, una comisión nombrada por médicos, practicantes y enfermeros de esta entidad se puso en contacto con Cortezo para comunicar las reivindicaciones económicas que exigían a cambio de arriesgar sus vidas en lo sucesivo. En los días previos, el tifus exantemático se había cobrado las vidas de un médico, un enfermero, tres ordenanzas, dos camilleros y una Hermana de la Caridad que prestaban servicio en el establecimiento. Cortezo esquivó el problema, cediendo responsabilidades al Gobierno, a la Diputación Provincial y al Ayuntamiento y planteando tan solo la concesión de gratificaciones de 75 pesetas mensuales a todos los trabajadores. Sin duda alguna, los más perjudicados eran los enfermeros, a quienes se ofrecían exiguos jornales de entre cinco y seis reales diarios. En cuanto a los médicos y los practicantes, su trabajo diario en el hospital les llevó a perder su clientela particular, quedando recluidos en el recinto para evitar nuevos contagios ${ }^{44}$.

El abandono en que quedaron algunos de los afectados era cada vez más significativo a pesar de las alabanzas de Cortezo a los servicios prestados por el Laboratorio Municipal de Higiene. Esta entidad practicó 1.208 operaciones de desinfección por causa de tifus exantemático entre los meses de mayo y agosto de 1903, ya fueran por su propia iniciativa o por solicitudes procedentes del propio vecindario, de médicos particulares, de facultativos de la Beneficencia Municipal, de Subdelegaciones de Medicina de los distritos o, en los casos menos representativos, de las autoridades ${ }^{45}$. A estos trabajos habría que añadir las desinfecciones que se practicaron con carácter preventivo y las operaciones de esterilización de las ropas de los afectados y de sus familiares y personas más cercanas ${ }^{46}$. Sin embargo, el carácter nada desdeñable de las tareas acometidas por este organismo no es óbice para no abordar los problemas asistenciales que existieron en los primeros meses de embate epidémico.

${ }^{43}$ El País, 27 de mayo de 1903 y El Imparcial, 4 de junio de 1903.

44 El Liberal, 11 de junio de 1903 y Heraldo de Madrid, 12 de junio de 1903.

45 En concreto, el Laboratorio Municipal de Higiene realizó 300 desinfecciones en mayo, 400 en junio, 276 en julio y 232 en agosto de 1903. En: Boletín del Laboratorio Municipal de Higiene de Madrid, Madrid, Imprenta Municipal, vol. 3, 1903.

${ }^{46}$ Sobre el servicio de desinfección del Laboratorio Municipal véase: Chicote, 1903. 
Gráfico 2. Desinfecciones practicadas por el Laboratorio Municipal de

Higiene de Madrid en 1903 según el tipo de enfermedad declarada

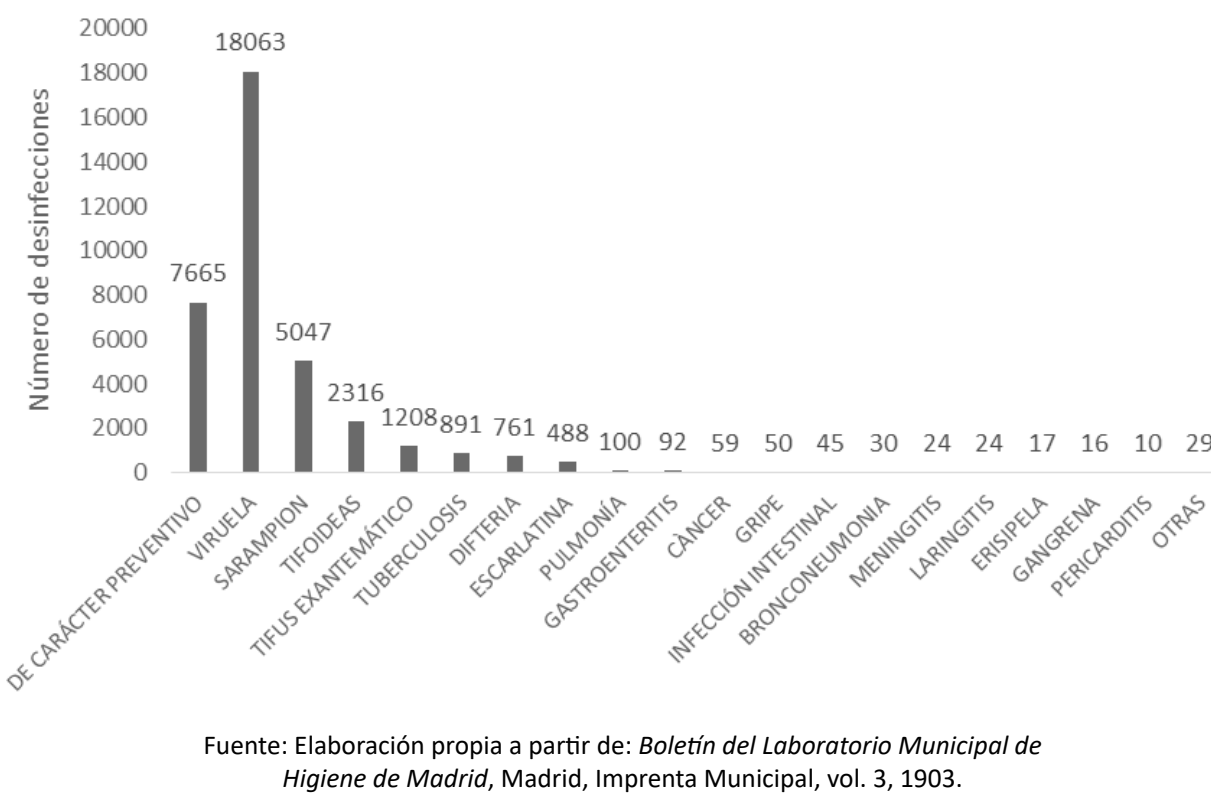

La prensa no tardó en airear casos particulares, aunque significativos, como el de Patricio Moreno, jornalero que habitaba en la calle del Espino $n$ o 6. Su esposa se encontraba atacada del tifus en el Hospital del Cerro del Pimiento. Este manifestó al diario El Imparcial el día 23 de mayo que uno de sus hijos, de siete años de edad, había comenzado a manifestar los síntomas de la enfermedad sin que ello fuera causa suficiente para quedar admitido en el Hospital Provincial, a donde fue conducido inicialmente. Patricio mostraba su pesar por haberse visto obligado a llevarlo de nuevo a su casa, en la que carecía de los medios precisos para proporcionarle los necesarios cuidados ${ }^{47}$. Similar era el caso de Jenara León, residente en la calle Fernández de los Ríos, a escasa distancia del Hospital del Cerro del Pimiento. Sintiéndose enferma, acudió acompañada por su marido en la mañana de ese mismo 23 de mayo al Hospital de la Princesa. Jadeante y solicitando ser admitida de inmediato, fue redirigida al Hospital Provincial sin ayuda sanitaria. La travesía que siguió hasta su internamiento en el hospital epidémico fue reproducida con detalle en el Heraldo de Madrid:

Habiéndosele manifestado que se dirigiese al Hospital Provincial, tuvo entonces que recorrer un camino amargo, paseando el tifus por todas las calles de Madrid, a

${ }^{47}$ El Imparcial, 23 de mayo de 1903. 
pie, extenuada, sin fuerzas, hasta que llegó al Hospital Provincial, a la una de la tarde, y fue admitida en el acto y reconocida por el médico de guardia Señor Ayora, quien ordenó su traslado inmediato al Cerro del Pimiento. Jenara León llevaba en su casa ocho días enferma y a última hora de esta tarde ha sido conducida a los pabellones del $\mathrm{Cerro}^{48}$.

Los traslados de los atacados por la epidemia hasta el hospital desde diferentes puntos de la ciudad se hicieron cada vez más complicados. Los problemas venían ya planteados de antemano con los mecanismos seguidos en los desplazamientos desde los asilos y los domicilios particulares hasta su destino final, situado en una zona atestada de desniveles y terraplenes. Las irregularidades fueron manifiestas desde la propia destrucción del Asilo de la Montaña, pues aunque buena parte de los enfermos fueron trasladados en camillas del centro y de la Casa de Socorro del Distrito de Palacio, otros se negaron a ello y acudieron al hospital por su propio pie. A finales de mayo de 1903 una comisión de vecinos de la calle de Leganitos acudió a la redacción de El País para comunicar que las camillas que conducían tíficos al Cerro del Pimiento hacían, por lo general, paradas en la Plaza de Leganitos, próxima a la actual Plaza de España y lugar donde los niños del barrio jugaban todas las tardes, lo que constituía un riesgo potencial de infección obviado por las autoridades municipales ${ }^{49}$.

Cortezo había justificado anteriormente las dificultades presentadas en el servicio de traslación de enfermos amparándose en la imposibilidad de hacerlo en furgones, por carecer de ellos la Sanidad Civil y por tenerlos completamente ocupados para el servicio de ambulancias la Sanidad Militar. En un primer momento, la Dirección General de Sanidad intentó gestar un acuerdo con los caleseros y los dueños de ómnibus de la ciudad para regularizar la conducción de los atacados, pero estos se negaron rotundamente a alquilar sus vehículos para tales menesteres ${ }^{50}$. La contratación de furgones y carruajes militares para este servicio se haría esperar hasta finales del primer trimestre de 1904.

Tal y como se había pronosticado en un primer momento, las primeras etapas críticas de la epidemia de tifus exantemático en Madrid se vivieron en los meses de junio, julio y agosto de 1903 (30, 32 y 19 fallecidos por la enfermedad, respectivamente). Los libros de defunciones del Ayuntamiento de Madrid permiten observar las características de los atacados y los espacios donde incubaron la enfermedad antes de su traslado al Hospital del Cerro del Pimiento, cuya influencia es, pese a todo, decisiva para explicar el mayor número de muertes del distrito de la Universidad. El análisis micro de la epidemia sirve para detectar su concentración en zonas particularmente densificadas de la parte sur del casco antiguo, como los barrios de

\footnotetext{
48 Heraldo de Madrid, 23 de mayo de 1903

49 El País, 29 de mayo de 1903.

50 El Liberal, 26 de marzo de 1903.
} 
Calatrava y Humilladero en el distrito de la Latina, el de Caravaca en Inclusa y el de Primavera en Hospital, definidos por el hacinamiento en casas de vecindad y por la proliferación de casas de dormir en las que existía una gran rotación de integrantes de las clases menesterosas. En esos tres meses cruciales de 1903 también rindió un notorio tributo a la epidemia el barrio de Gasómetro perteneciente al Ensanche Sur, con gran protagonismo para la miserable barriada del Cristo de las Injurias en su demarcación.

A partir de septiembre de 1903, el impacto de la enfermedad comenzó a remitir de manera considerable, hasta el punto de que la prensa periódica y las publicaciones médicas especializadas hablaron abiertamente de una extinción definitiva del problema sanitario a finales de año. Pero aún y con todo, entre los meses de mayo y diciembre, el tifus exantemático causó 132 muertes en Madrid, siendo las cohortes etarias más afectadas las comprendidas entre los 25 y los 29 años y las adultas a partir de los 40 años. Los distritos más afectados fueron Hospital y Universidad, donde se ubicaban el Hospital Provincial y el Hospital del Cerro del Pimiento respectivamente. El escaso protagonismo del resto de zonas nos llevaría a apuntar un éxito relativo para la campaña sanitaria emprendida por Cortezo, a la hora de evitar una multiplicidad de focos de infección.

Gráfico 3. Número de fallecidos por tifus exantemático en Madrid en 1903 por meses

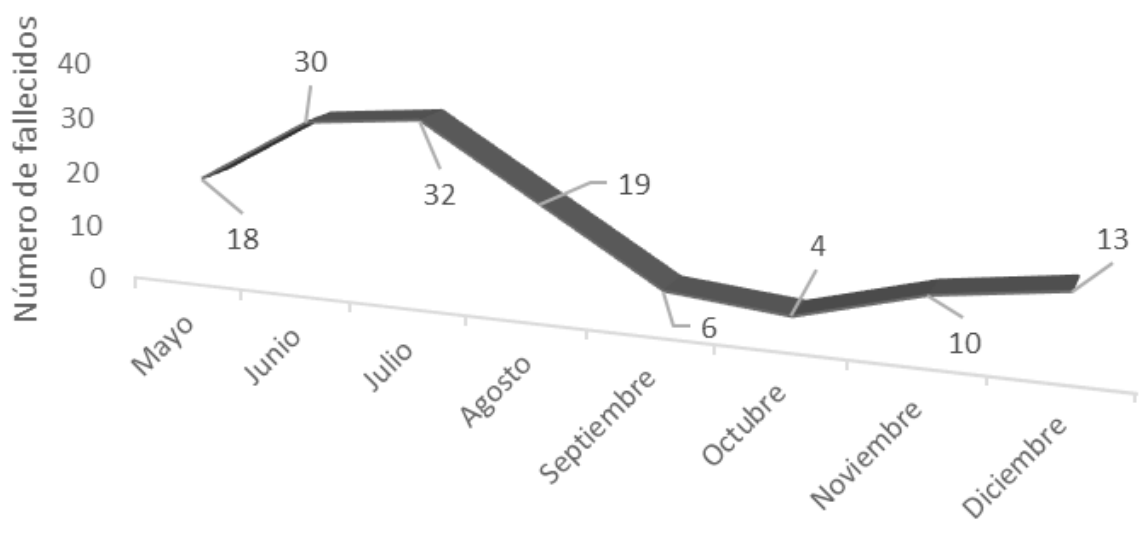

Fuente: AVM, Estadística, Libro de defunciones de Madrid de 1903 y AYUNTAMIENTO DE MADRID (1904), Estadística Demográfica de 1903, Madrid, Imp. Municipal. 


\section{Gráfico 4. Número de fallecidos por tifus exantemático en Madrid en 1903 por edades}

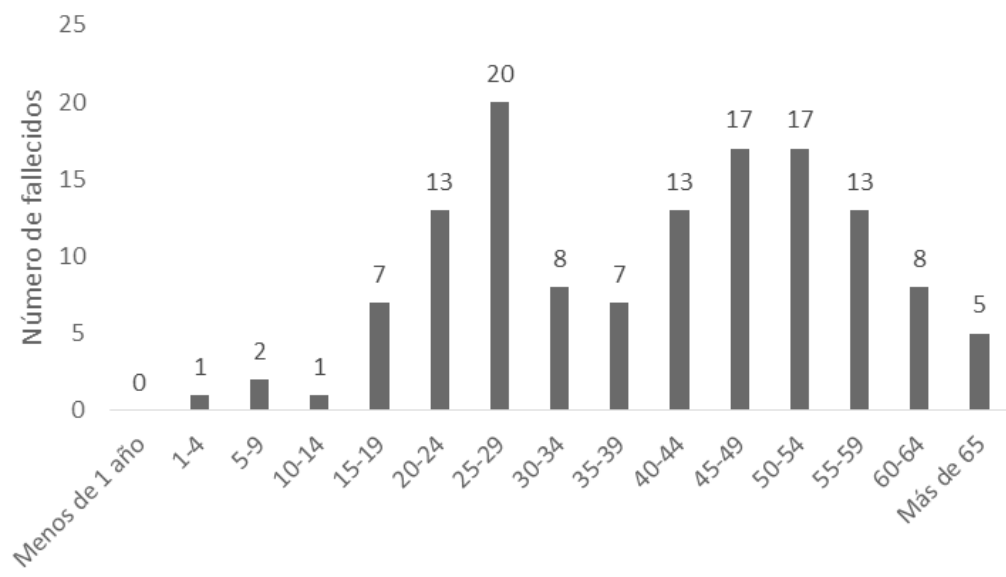

Fuente: AVM, Estadística, Libro de defunciones de Madrid de 1903 y AYUNTAMIENTO DE MADRID (1904), Estadística Demográfica de 1903, Madrid, Imp. Municipal.

\section{Gráfico 5. Muertes por tifus exantemático en Madrid por distritos (1903)}

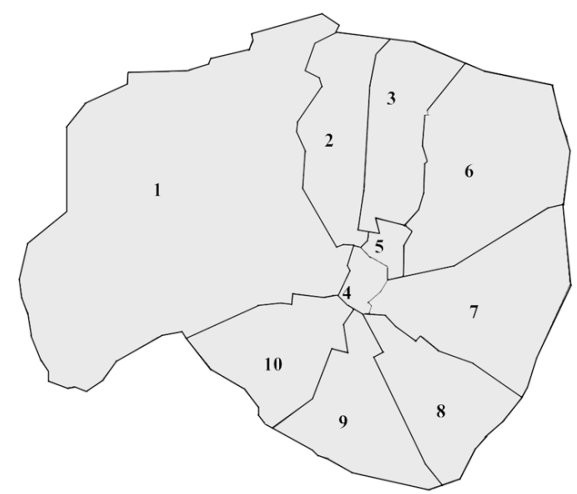

$\mathrm{N}^{\circ}$ DE MUERTES POR TIFUS EXANTEMÁTICO POR DISTRITOS

$$
\begin{array}{r}
\text { 1. PALACIO: } 17 \text { FALLECIDOS } \\
\text { 2. UNIVERSIDAD: } 33 \text { FALLECIDOS } \\
\text { 3. CHAMBERI: } 8 \text { FALLECIDOS } \\
\text { 4. CENTRO: } 7 \text { FALLECIDOS } \\
\text { 5. HOSPICIO: } 5 \text { FALLECIDOS } \\
\text { 6. BUENAVISTA: } 2 \text { FALLECIDOS } \\
\text { 7. CONGRESO: } 6 \text { FALLECIDOS } \\
\text { 8. HOSPITAL: 14 FALLECIDOS } \\
\text { 9. INCLUSA: } 18 \text { FALLECIDOS } \\
\text { 10. LATINA: } 17 \text { FALLECIDOS }
\end{array}
$$

Leyenda: El mapa contabiliza las muertes acaecidas en el Hospital Provincial y en el Hospital del Cerro del Pimiento en función del lugar de procedencia del enfermo, para evitar resultados distorsionados en los distritos de Hospital y Universidad. Fuente: AVM, Estadística, Libro de defunciones de Madrid de 1903. 
Aunque la ciudad se vio sometida a otra epidemia todavía más mortífera durante los últimos meses de 1903, relacionada con la viruela (Monmeneu, 1904), había ciertas esperanzas entre las autoridades municipales de revertir la situación en términos de saneamiento e higienización. Éstas venían explicadas por una subvención de capitalidad de dos millones de pesetas votada por las Cortes en el mes de diciembre, con la que el consistorio aumentaría su presupuesto quedando en disposición, si bien solo teóricamente, de afrontar sus problemas sanitarios y relacionados con la crisis laboral ${ }^{51}$.

\section{EL RECRUDECIMIENTO DE LA EPIDEMIA EN 1904 Y SU FASE FINAL EN 1905}

El 16 de diciembre de 1903 se celebró una sesión en el Senado casi íntegramente dedicada al estado sanitario de Madrid. En ella destacó la interpelación del médico y senador vitalicio Ángel Pulido al ministro de la Gobernación, condicionada por el reguero de fallecidos que la epidemia de viruela estaba dejando en la capital. La ausencia de medios para combatirla se reflejaba en cómo el número de atacados había crecido imparablemente desde junio hasta esa fecha y, sobre todo, en el aspecto que presentaba el Hospital Provincial, principal núcleo receptor de los variolosos en inapreciables condiciones de aislamiento. Pero para Pulido, la gota que había colmado el vaso tenía que ver con el reciente caso de un comerciante atacado de tifus exantemático llevado inicialmente al Hospital de la Princesa cuando se detectó la enfermedad. Los médicos de este recinto, ateniéndose a disposiciones reglamentarias, prohibieron su ingreso y le condujeron al Hospital Provincial, donde falleció al poco de llegar. La situación era particularmente preocupante, habida cuenta de la extraordinaria acumulación de enfermos en el segundo centro, que había comenzado incluso a transformar las galerías de ventilación situadas en las buhardillas en improvisadas salas para colocar nuevas camas.

Pulido pintó a los senadores un oscuro cuadro que revelaba la falta de dispositivos médicos de la ciudad y la necesidad de superar el atraso con respecto a otras grandes capitales europeas mediante el desarrollo de unos servicios hospitalarios totalmente distinguibles de los existentes en aquellos momentos. La cámara conoció por su voz la necesidad de emprender la construcción de un hospital de epidemias moderno y carente de las deficiencias cada vez más palmarias presentadas por el del Cerro del Pimiento, cuyo grado de abandono había crecido durante el segundo semestre de 1903:

51 Paralelamente, las Cortes decidieron nombrar una comisión mixta de concejales y representantes de otras corporaciones oficiales para que intervinieran en el gasto del crédito. En: El Siglo Médico, no 2.617, 7 de febrero de 1904, pág. 97. 
Se dirá que en la angustia en que estamos ha de prestar (el Hospital del Cerro del Pimiento) todavía algunos servicios para llevar allí enfermos, y yo puedo decir al Sr. Ministro de la Gobernación que esto se ha resuelto, según tengo entendido, por virtud de un acuerdo tomado por el alcalde, el director de Sanidad y el presidente de la Diputación o el gobernador, no recuerdo cuál; pero, en fin, creo que por estas tres entidades, y que este hospital podrá servir, a lo sumo, para salir del paso en el transcurso de un mes, de mes y medio o de dos meses, exponiendo a los enfermos que allí vayan a consecuencias muy lamentables, careciendo completamente de condiciones higiénicas; porque allí los cristales han desaparecido (...); las persianas están deshechas en gran parte (...); las condiciones de calefacción son sumamente malas y, como he dicho anteriormente, falta todo lo relativo al abastecimiento de aguas y evacuación de aguas inmundas, cosa tan necesaria e indispensable en un hospital, y son malas las condiciones de solidez de aquellos pabellones (...). Por consiguiente, hay que partir del principio de que el Cerro del Pimiento, a lo sumo, podrá servir para una angustia o para una necesidad del momento, para descargar aquellas buhardillas del Hospital General de la aglomeración de enfermos variolosos que allí existen, pero en manera alguna para responder de un modo definitivo y permanente a esas necesidades de la sanidad pública en que nos estamos ocupando ${ }^{52}$.

Las declaraciones de Pulido apuntaban a la necesidad de acabar con la dinámica de combatir las enfermedades infecto-contagiosas por medio de cuarentenas que no suponían más que meros parches para una administración sanitaria escasamente celosa en sus disposiciones. La única forma de afrontar con garantías el control de brotes epidémicos pasaba por la edificación de un hospital de enfermedades infecciosas convenientemente preparado en el que todas las clases sociales encontraran un tratamiento y aislamiento adecuados. La complejidad de la situación sanitaria de Madrid amenazaba con intensificarse si no se acometía esta transformación y las advertencias de Pulido no tardaron en hacerse realidad. En febrero de 1904 se registraron quince nuevas defunciones por tifus exantemático que anticipaban un nuevo y todavía más agresivo recrudecimiento de la epidemia, ya plenamente desatada en marzo con la muerte de 46 personas $^{53}$. El mayor número de invasiones se produjo, como apenas un año antes, en las instalaciones del Hospital Provincial, lo que a todas luces mostraba el escaso control preventivo que había existido en el mismo. Durante el mes de marzo quedaron contagiados un médico, cuatro alumnos internos y doce mozos del establecimiento sanitario, al margen de los pacientes enfermos que iban llegando y siendo inmediatamente trasladados al Hospital del Cerro del Pimiento ${ }^{54}$. Sin embargo, muchos de los que ya se habían visto invadidos

52 Diario de las Sesiones de las Cortes. Senado, no 99, 16 de diciembre de 1903, pp. 1.718-1.719.

53 El Liberal y El País, 23 de marzo de 1904.

${ }^{54}$ Carlán, Diego: «Otra vez el tifus», en: El Siglo Médico, no 2.624, 27 de marzo de 1904, pág. 213 y Carlán, Diego: «La epidemia reinante», en: El Siglo Médico, no 2.625, 3 de abril de 1904, pág. 230. 
por la enfermedad en el primero de los recintos hospitalarios no tuvieron más remedio que permanecer en aquel por la falta de camillas para facilitar su traslado y por la carencia de camas en el del Cerro del Pimiento ${ }^{55}$.

La prensa se hizo nuevamente eco del problema y comenzó a especularse sobre las posibles causas del recrudecimiento de la epidemia. Algunos de las más reseñables tenían que ver con la reciente aperturas de las Escuelas-Asilos, inauguradas el 1 de febrero de 1904 y dedicadas a albergar a los cerca de dos centenares de golfos que se recogieron a lo largo de toda la ciudad en las semanas anteriores y con los escasos controles higiénico-sanitarios realizados en los asilos de mendigos de Santa Ana, Santa Cristina y Norte, de donde habían salido importantes contingentes de atacados hacia el Hospital del Cerro del Pimiento ${ }^{56}$. Otros guardaban relación con la aparición de nuevos focos de infección en ciertas calles que ya habían sido afectadas en los momentos iniciales de la epidemia, como Alonso Cano y Virtudes en el norte y Peña de Francia, Mediodía Grande, Mediodía Chica, Arroyo de Embajadores y algunas otras del sur del casco antiguo ${ }^{57}$. Pero, sobre todo, lo que reflejaba el regreso del tifus exantemático era el abandono de la preocupación por la enfermedad y por la salubridad pública tras concluir el primer brote epidémico, como señaló Ramón Comas, alumno interno del Hospital de San Carlos ${ }^{58}$.

Las repercusiones del segundo brote fueron terribles. Los desplazamientos de enfermos registraron mayores deficiencias y negligencias que durante el año anterior. Así se precisaba en La Correspondencia de España $a^{59}$ y, sobre todo, en la carta enviada por Carlos Carazo, alumno interno de la Facultad de Medicina, a El Imparcial, que confirmó los errores cometidos en el control de la epidemia. Las irresponsabilidades cometidas por las autoridades volvieron aflorar desde febrero de 1904, conduciéndose a los atacados en camillas por las calles en los momentos en los que más elevada era la afluencia de transeúntes:

55 Diario Oficial de Avisos de Madrid y El Imparcial, 24 de marzo de 1904.

${ }^{56}$ La mayoría de los niños acogidos en las Escuelas-Asilo tenían una edad de entre ocho y trece años, siendo menor la cifra de jóvenes de catorce a veinte, si bien todos compartían un origen común, determinado por la orfandad o por circunstancias vitales traumáticas que habían conducido a la mendicidad. Según los datos recabados por Ramón Comas procedentes del Hospital del Cerro del Pimiento, desde el 19 de febrero hasta el 25 de marzo ingresaron en el recinto 44 enfermos de tifus exantemático llegados de las Escuelas-Asilo (21 de la situada en la calle Garcilaso, 26 de la del Paseo del Rey y 16 de la ubicada en Calvo Asensio) del total de 63 que lo hicieron entonces (14 casos más con fiebre infecciosa, 4 con fiebres tifoideas y uno con viruela). En: El Imparcial, 18 de febrero de 1904, El Correo Español, 26 y 29 de marzo de 1904, Heraldo de Madrid, 27 de marzo de 1904 y El Día, 30 de marzo de 1904.

${ }^{57}$ La Correspondencia de España, 24 y 25 de marzo de 1904.

${ }^{58}$ El Correo Español, 26 de marzo de 1904.

59 La Correspondencia de España, 24 de marzo de 1904. 
Los mozos que conducían las camillas, rendidos al peso y abrumados de fatiga, descansaban de momento a momento, y los curiosos se agrupaban en torno del infeliz enfermo. Íbase de este modo distribuyendo por Madrid la semilla morbosa. Estas camillas han sido llevadas por las aceras de la calle de Atocha, plaza del Matute, calles del Príncipe, Preciados, Leganitos, Mayor, etc., donde constantemente en el centro del día hay un número crecido de gentes que, sin fijarse en ello, eran rozadas por las camillas; así se explica que sea tan grande el número de personas acomodadas que están sufriendo la infección. Para que se forme una idea exacta del desarrollo que ha alcanzado la epidemia, diré que actualmente están enfermos de esa horrible dolencia cuatro médicos, siete estudiantes de medicina, de los cuales uno ha fallecido y otro está gravísimo. De los mozos que prestan servicio en el Cerro del Pimiento, sólo dos han conseguido hasta ahora librarse del contagio: tres de ellos estaban hace tres días en grave situación ${ }^{60}$.

Para tratar de la conducción de enfermos al Cerro del Pimiento se celebró una conferencia entre el Gobernador Civil de la Provincia de Madrid y el presidente de la Diputación Provincial. El objetivo que se dilucidó en esta reunión fue plantear la solicitud al Ministerio de la Guerra de coches de Sanidad Militar para facilitar los desplazamientos, petición a la que se accedió sin dificultades ${ }^{61}$. Las autoridades también pusieron en marcha nuevas medidas previsoras, orquestadas en primer término por la Junta Provincial de Sanidad, que ordenó la inmediata desinfección de las salas del Hospital Provincial donde se hubiesen detectado casos de tifus y que pronunció nuevas medidas para el control y aislamiento de los enfermos. Primero, se determinó colocar carteles en las puertas de las casas donde hubiese enfermos de tifus anunciando la presencia en ellas de la enfermedad y el riesgo de entrar en las mismas. En segundo término, se decretó el traslado de tíficos al Cerro del Pimiento exclusivamente en furgones convenientemente desinfectados después de cada viaje. En tercer lugar, se ordenó que una vez ocurrida la defunción de un atacado de tifus fuera trasladado de inmediato al depósito de cadáveres del hospital en la misma forma en que se acordó durante la epidemia de viruela en los meses de invierno de 1903 y $1904^{62}$. Y finalmente, se prohibió terminantemente cualquier visita al Hospital del Cerro del Pimiento en lo sucesivo, se recordó a los médicos particulares la obligación de informar de todos los casos de tifus en el momento preciso de hacer el diagnóstico y aun teniendo mínimas

60 El Imparcial, 24 de marzo de 1904.

61 Diario Oficial de Avisos de Madrid, 24 de marzo de 1904.

62 En concreto, se precisó la necesidad de practicar no sólo una desinfección diaria en todo recinto hospitalario o vivienda en la que detectara un caso de tifus una vez terminada la enfermedad por curación o muerte, sino además, otra desinfección especial del suelo, pared y techo de la cámara del atacado. En: El Día, 25 de marzo de 1904. 
sospechas de la enfermedad y se estableció la desinfección y quema de las ropas del tífico y de otros objetos de su habitación al terminar la enfermedad ${ }^{63}$. A partir de este momento, y por Real Orden del Ministerio de la Gobernación, la dirección de los trabajos a emprender contra la nueva epidemia quedó en manos del doctor Eloy Bejarano.

Los primeros informes de Bejarano sobre el estado de la epidemia fueron concluyentes. Los barrios amenazados por la enfermedad eran los llamados «extremos», situados en la periferia del Ensanche Norte (en torno a la zona de Cuatro Caminos y Bellas Vistas) y, sobre todo, los concentrados en los distritos de la Latina e Inclusa, donde a su juicio solo existía un medio de cortar el mal de raíz: derribar manzanas enteras que comprendieran las casas ruinosas, viejísimas y sucias que abundaban en toda la demarcación administrativa. En los barrios del centro urbano también se estaban produciendo casos, pero de manera más aislada, quedando además sometidos a un mayor control y siendo sistemáticamente denunciados por las autoridades médicas de los distritos. Según Bejarano, eran episodios generalmente benignos que respondían al «leve contacto establecido con personas aún convalecientes de la enfermedad en iglesias, teatros, cafés y demás sitios donde acuden gentes de todas las clases sociales ${ }^{64}$.

No tardó Bejarano en determinar medidas rigurosas para el control del nuevo brote. Entre ellas destacaban la exigencia de una mayor escrupulosidad en los diagnósticos médicos del Hospital Provincial, evitando posibles contagios mediante un envío inmediato de los tíficos al Hospital del Cerro del Pimiento; operaciones de aislamiento más estrictas en el traslado de los invadidos por la enfermedad (en furgones recubiertos en su interior de metal y de otro material y cuerpo de fácil y rápida desinfección); y concesión de vehículos para desplazamientos a las Casas de Socorro, demostrada la deficiencia y peligrosidad de las camillas que tradicionalmente utilizaban. A todo ello se sumaba la urgencia de desinfectar espacios que pueden actuar como focos de transmisión de la enfermedad (cafés, fondas y urinarios públicos) y de mostrar una actitud más implacable con los médicos particulares y subdelegados de medicina que no informaran de los casos de tifus registrados en los barrios de Madrid a las correspondientes autoridades sanitarias y al Laboratorio Municipal de Higiene ${ }^{65}$.

Paralelamente, Bejarano entró en contacto con el gobernador civil de la provincia de Madrid para imponer reglas más claras en el ingreso de enfermos de tifus exantemático en los hospitales. En este sentido se hizo presente la necesidad de que fueran sometidos a un reconocimiento más exhaustivo los enfermos que recibían asistencia médica en el Hospital del Cerro del Pimiento (por la creencia de

${ }^{63}$ Heraldo de Madrid, 23 de marzo de 1904 y El Día, 25 de marzo de 1904.

${ }^{64}$ El Imparcial, 26 de marzo de 1904.

${ }^{65}$ La Época, 29 de marzo, 2 de abril y 4 de abril de 1904. 
que una parte de ellos no estaban en realidad atacados de tifus, con el consiguiente riesgo de que pudieran contagiarse) y de dejar operativa una sala de observación y diagnóstico en el Hospital Provincial para los que llegaban procedentes de las Escuelas-Asilos o de los depósitos de mendigos municipales. El objetivo en este último caso era sencillo: evitar el rechazo automático de estos individuos en el recinto hospitalario, medida que predominó en el mes de marzo ${ }^{66}$.

Junto a la labor de Bejarano, no debe olvidarse la reacción del Ayuntamiento de Madrid ante el recrudecimiento de la epidemia. En el pleno municipal del 29 de marzo se fijaron normas de actuación para combatir el problema, destacando las planteadas en la limpieza de la vía pública (se determinó que precediera siempre el riego al barrido de la vía pública y que este nunca se hiciera en seco y se prometieron ciertos progresos en el tratamiento de las basuras de los espacios periféricos considerados como «peligrosos» desde un punto de vista higiénico-sanitario); en la limpieza del alcantarillado (fijando reglas de evacuación de pozos negros para los propietarios de las fincas que contasen con ellas y proporcionando al Laboratorio Municipal de Higiene los medios económicos necesarios para elaborar virus raticidas que pudieran distribuirse entre todo el vecindario) y en la observación de las condiciones de los alimentos consumidos por la población (intensificando las tareas de inspección del laboratorio en establecimientos de toda clase, mercados, estaciones de ferrocarril, fielatos del extrarradio y estancias del Matadero ${ }^{67}$.

Pero del consistorio se esperaban, sobre todo, disposiciones más tajantes y efectivas en lo que respectaba a la desinfección de las casas y espacios urbanos donde hubiera mayor concurrencia pública. Al margen de determinarse la absoluta obligatoriedad de este tipo de acción en casos de tifus exantemático y en los de toda clase de enfermedades contagiosas, se aumentaron las competencias del Laboratorio Municipal de Higiene en la lucha contra la epidemia. Ante todo, debía cumplirse a rajatabla el bando publicado por la alcaldía de Madrid el 10 de diciembre de 1901, que estipulaba como medida preventiva la obligatoria desinfección de los cuartos que se desalquilaban, de las ropas usadas que se pusieran a la venta en el Monte de Piedad, de las casas de préstamos, de los puestos y locales del Rastro y de los trapos viejos antes de hacer su clasificación en los establecimientos dedicados a esta industria. El laboratorio debía encargarse de practicar las desinfecciones no solo en aquellos locales donde existiesen o hubiesen existido enfermos, sino también, y como medida preventiva, en locales insalubres donde hubiese tendencia a la aglomeración de personas (asilos, casas de dormir, cafetines, etc). En aquellas vías públicas donde se hubiesen declarado casos de tifus exantemático, se encargaría de su saneamiento mediante riegos con soluciones antisépticas, haciéndose esta tarea más extensiva en las viviendas de los atacados (practicándola en habitaciones,

\footnotetext{
66 El Día, 5 de abril de 1904.

67 La Época, 30 de marzo de 1904.
} 
objetos y ropas encontrados en las mismas, castigándose económicamente su venta o cesión sin haber sido previamente desinfectadas). En caso de fallecimiento, la desinfección comprendería también la de los paños utilizados en la cámara mortuoria del enfermo y la de los coches fúnebres.

Las disposiciones del Ayuntamiento se hicieron particularmente precisas con respecto a la higiene de las viviendas. De manera sistemática, los inspectores del laboratorio debían dar parte a los tenientes de alcalde de todas aquellas faltas de limpieza que encontrasen en las casas y en sus patios interiores, castigando severamente a sus propietarios si no se atenían a las normas marcadas con anterioridad. La supervisión debía ser particularmente rigurosa en los espacios residenciales de las clases populares, obligando a los caseros a su frecuente blanqueo y a dotarlas de las oportunas condiciones de ventilación. La alcaldía también planteó en este momento entrar en diálogo con la Comisión de Reformas Sociales, creada en 1903, con el objeto de estudiar un proyecto de casas salubres y económicas que permitiera abordar la necesaria destrucción de las fincas insalubres existentes en ciertos barrios del sur del casco antiguo. Y por último, se exigió la inmediata formación de una estadística sanitaria de casas y habitaciones, la inexorable tarea para los tenientes de alcalde de girar visitas frecuentes a solares, establecimientos comerciales e industriales y casas de vecindad y dormir existentes en sus respectivos distritos y el nombramiento de veinte médicos supernumerarios que intensificaran las tareas de atención a los enfermos contagiosos de todas las casas insalubres de cada demarcación administrativa (incluyendo hospederías, casas de dormir y cuartos que no debieran ser habitados bajo circunstancia alguna).

Finalmente, desde la municipalidad también se contemplaban como acciones urgentes la inspección médica y limpieza diaria de las Escuelas-Asilos, la comunicación continua entre los jefes de las Casas de Socorro y los inspectores del Laboratorio Municipal en los casos de detección de tifus exantemático y de otras enfermedades contagiosas por parte de los primeros, la construcción de nuevos furgones para el traslado de los enfermos (siguiendo el modelo de las ambulancias parisinas) y la publicación de edictos que recordaran al vecindario su necesaria cooperación en la campaña ${ }^{68}$. Buena parte de las medidas municipales planteadas en el pleno del 29 de marzo de 1904 terminaron plasmándose oficialmente en un bando publicado el 14 de abril ${ }^{69}$.

Pero los buenos propósitos de Bejarano y del consistorio, la mejora de las condiciones de traslado y cuidado de los enfermos y la intensificación de las desinfecciones estuvieron lejos de producirse. A pesar de que se determinó la obligatoriedad de utilizar únicamente furgones de Sanidad Militar para estas operaciones, muchos de los desplazamientos realizados hasta el Cerro del Pimiento a finales de

${ }^{68}$ La Época, 30 de marzo de 1904.

${ }^{69}$ El Día, 15 de abril de 1904. 
marzo de 1904 seguían produciéndose en camillas. La justificación era sencilla, pues solo se había concedido un furgón para el desarrollo del servicio de epidemias, lo que suponía un claro testimonio de la absoluta indefensión higiénica a la que se enfrentaba la ciudad. La comparación con París, donde recientemente se habían detectado casos de tifus, sacó a relucir la nula eficacia de las autoridades en la solución de esta cuestión:

Poco hace que se presentaron en algunos hospitales episodios de tifus. No pasaban de treinta, según las referencias de los periódicos. La alarma fue, sin embargo, grande. Aquella ciudad, de tres millones de habitantes, consideró la presencia de la epidemia como el hombre sano y culto la aparición en su cuerpo de un estigma de enfermedad. Las precauciones sanitarias adoptadas por el servicio sanitario de París han llegado a lo que aquí parecía inverosímil. Las casas en que vivían los atacados fueron aisladas, los muebles y las ropas quemados previa la indemnización correspondiente. Así es como se procede cuando la vida del ciudadano y la salud pública son estimadas en todo su valor. Pero entre nosotros, la existencia de aquel que perece bajo la acometida de la fuerza pública en un motín y la del que cae herido de muerte en el contagio epidémico constituyen cantidades despreciables. Esta es la diferencia que existe entre los pueblos verdaderamente cultos y los que se hallan a la mitad en el camino de la civilización ${ }^{70}$.

Sin embargo, no era este el problema más grave. Muchas de las camillas utilizadas para el traslado de tíficos se empleaban también para conducir al Hospital Provincial a otra clase de enfermos sin que previamente se procediera a su desinfección ${ }^{71}$. Asimismo, la prensa inspeccionó la forma en que los carruajes realizaban el servicio comprobando que la recogida de los afectados en sus domicilios particulares no iba acompañada por su conducción inmediata al hospital. Por el contrario, los enfermos permanecían en el carruaje durante horas, no siendo trasladados hasta que el furgón estaba completamente abarrotado. La falta de recursos para contratar más vehículos provocaba que los afectados llegaran al hospital en condiciones de extrema gravedad o incluso ya fallecidos, no recibiendo alimentos o medicinas durante ese intervalo de tiempo ${ }^{72}$.

El enorme impacto que la epidemia estaba teniendo sobre el personal médico y de enfermería del Hospital Provincial y del Hospital del Cerro del Pimiento y la nula eficacia de las medidas adoptadas por las autoridades generó una inmediata reacción de los estudiantes internos de la Escuela de San Carlos. Éstos habían

70 El Imparcial, 26 de marzo de 1904.

71 En el distrito de la Latina, por ejemplo, se denunció la utilización de una misma camilla para trasladar primero a un enfermo de tifus de la calle de Mira el Río hasta el Hospital del Cerro del Pimiento e inmediatamente después a una enferma desde la calle de la Paloma a la sala de cirugía del Hospital Provincial. En: El Imparcial, 25 de marzo de 1904.

72 El País, 14 de abril de 1904. 
perdido a cuatro compañeros en las semanas anteriores y ante el peligro de los contagios y las nulas garantías de higiene y seguridad en el Hospital Provincial decidieron no asistir a las clases impartidas en el Colegio de San Carlos, no volviendo a ellas hasta que "cese esta epidemia o podamos con tranquilidad confiar en las medidas higiénicas adoptadas, para evitar el contagio, no solo nuestro, sino del resto de la población, en cuyo seno vivimos ${ }^{73}$. El claustro de Medicina respondió al manifiesto estudiantil con medidas muy vagas que en ningún caso afrontaban el problema de raíz. En este sentido, se tomaron tres decisiones: mantener abiertas las clínicas, evitar la relación de todos aquellos estudiantes que estuviesen en el Cerro del Pimiento con sus compañeros en las clases y comprar nuevas estufas de desinfección ${ }^{74}$. La decisión vino además apoyada por las acciones emprendidas justo en el día anterior por Bejarano, que comunicó a la prensa el infundado temor manifestado por los escolares de medicina negando la existencia de enfermos tíficos en los establecimientos que señalaban y precisando al Ministerio de la Gobernación la ausencia de motivos sólidos para la suspensión de las clases ${ }^{75}$.

La inacción del Ayuntamiento de Madrid también se hizo palpable a pesar de la trascendencia de las medidas inicialmente planteadas. Sin ir más lejos, podía vislumbrarse en las quejas del vecindario de ciertas zonas, como la comprendida en torno a la Plaza de la Constitución (actual Plaza Mayor). Los habitantes de los espacios próximos resaltaron las aglomeraciones de golfos y mendigos en los soportales de la plaza y los primeros casos de tifus exantemático detectados entre ellos, sin que los traslados al Hospital del Cerro del Pimiento se practicaran de manera organizada $^{76}$. Algo similar hicieron algunos vecinos del barrio de Argüelles, que enviaron cartas a El Imparcial denunciando el abandono higiénico en que se dejaban las casas de los atacados por la epidemia en esa zona. Uno de los casos más sangrantes ocurrió en el número 61 de la calle de la Princesa, donde no se verificó desinfección alguna y donde las ropas de cama de la vivienda donde falleció la persona atacada permanecieron colgadas en uno de los balcones del patio interno del edificio durante toda una noche ${ }^{77}$. Lo más alarmante del caso es que no era la primera muerte ocurrida en un inmueble que desde la prensa se definió como un hormiguero humano, plagado de cuartos interiores de reducida extensión en los que habitaban familias de entre ocho y diez individuos ${ }^{78}$.

Pero problemas como el del número 61 de la calle de la Princesa eran perceptibles en otros muchos puntos de la ciudad. A mediados de mayo de 1904, en pleno

${ }^{73}$ El Correo Español, 7 de abril de 1904.

${ }^{74}$ La Época, 8 de abril de 1904.

${ }^{75}$ Heraldo de Madrid, 7 de abril de 1904.

${ }^{76}$ La Correspondencia de España, 8 de marzo de 1904 y El Imparcial, 9 de marzo de 1904.

77 El Imparcial, 12 de mayo de 1904.

78 El Día, 13 de mayo de 1904. 
apogeo de la epidemia, se descubrieron focos de tifus exantemático no declarados en tres casas del centro de Madrid (calles de Valverde, Aduana y Tetuán). El gobernador civil de Madrid se puso entonces en contacto con los subdelegados de Medicina de los distritos que integraban estas vías públicas para pedir explicaciones por no haberse tomado ni precauciones, ni medidas de higiene en esas viviendas. Sin embargo, la detección de los casos de tifus exantemático no solo dependía de las mencionadas autoridades. Debía existir una comunicación constante entre ellos y los médicos que asistían a los enfermos en las habitaciones. No eran pocos los casos en los que los segundos no daban parte de las atenciones practicadas a los primeros, situación que se mantuvo hasta que desde el Gobierno Civil se comenzaron a imponer multas económicas por desobediencia de los bandos municipales. La descoordinación entre las autoridades durante la campaña contra el tifus era absoluta y se veía todavía más perjudicada en la asistencia domiciliaria por la actitud de algunos propietarios e inquilinos de casas como la de la calle de la Aduana, donde a pesar de detectarse casos de tifus no se comunicó nada con respecto a este asunto ni a las autoridades médicas ni a las públicas para mantener la explotación económica clandestina del piso como casa de huéspedes ${ }^{79}$.

Por último, cabe señalar que el incremento del número de desinfecciones domiciliarias practicadas por el Laboratorio Municipal de Higiene no vino acompañado por una mayor eficiencia en las mismas. José González Campo, médico de la Beneficencia Municipal y encargado de la asistencia domiciliaria a los tíficos en algunas de las zonas más miserables del sur de Madrid, destacó sus carencias. Al margen de la candidez que se demostraba con el intento de evitar la propagación de los afectos infecciosos en las viviendas «vertiendo por los suelos con una regadera una solución de creolina o de cualquiera otra substancia», Ilamaba la atención de este especialista las rarísimas ocasiones en las que se procedía a la incineración de las ropas de los enfermos. No eran pocas las casas que no se desinfectaban de manera apropiada, como demostraban los contagios producidos justamente a raíz de una mudanza residencial a la vivienda de una persona previamente atacada o la reiteración de casos en inmuebles como el situado en el número 2 de Cristo de las Injurias, donde desde que principió la epidemia se detectaron más de treinta invasiones. González Campo corroboraba estas últimas afirmaciones detectando cómo los inquilinos de esta última casa habían Ilegado a adquirir tal hábito de reconocer la enfermedad que algunos se diagnosticaban por sí mismos, «no solicitando asistencia y yendo motu proprio a procurarse ingreso en el hospital ${ }^{80}$.

79 Diario Oficial de Avisos de Madrid, 15 de mayo de 1904.

${ }^{80}$ Malo de Poveda, Bernabé: «Origen, difusión y profilaxis de la actual epidemia tífica de Madrid. Conferencia dada en el Colegio de Médicos de esta provincia el 26 de mayo", en: El Siglo Médico, no 2.637, 26 de junio de 1904, pp. 428-431. 
Sin embargo, tampoco se debe olvidar que la creciente gravedad de la epidemia guardaba cierta relación con la ignorancia de unos preceptos profilácticos de higiene básicos a la hora de evitar el contagio por parte del vecindario de algunas de las principales zonas populares de Madrid. González Campo lo advirtió en sus visitas domiciliarias, comprobando que familias enteras compartían habitación e incluso camas con personas atacadas. Muchas de ellas tampoco daban parte de la enfermedad hasta casi dos semanas después de presentarse los primeros síntomas, lo que evidencia el completo desconocimiento del problema sanitario (González Campo, 1904, p. 250). En este sentido, se tardó demasiado tiempo en tomar una decisión trascendental, referente a la redacción de unas instrucciones populares sobre la profilaxis del tifus exantemático que detallasen las medidas necesarias para evitar el contagio de la enfermedad. Éstas fueron publicadas por la Sociedad Española de Higiene a comienzos de mayo de 1904, especificando su proliferación en casas «mal ventiladas que alojan gran número de individuos sucios, miserables y mal alimentados»; su contagio a escasa distancia, la brusquedad en la invasión de la enfermedad, su duración y los síntomas presentados en los atacados durante su fase de evolución y los mecanismos de prevención fundamentales. Entre estos últimos destacaban la constante aireación de las habitaciones, el lavado de la piel con agua caliente y jabón, la desinfección de la ropa y vestidos, una alimentación sana y suficiente y la constante apertura de los balcones y ventanas exteriores de las habitaciones en las que existieran tíficos. Una vez pasada la enfermedad, se recomendaba fehacientemente la desinfección general de los cuartos mediante la utilización de vapores de formol (así como el lavado de paredes, suelos y muebles con soluciones de cloruro de cal, sublimado o creolina). Finalmente, se estipulaban unas reglas concretas para todos aquellos que permanecieran en contacto con los atacados, ya fueran familiares o profesionales de la medicina. Para los segundos, era fundamental llevar blusas o trajes apropiados en las tareas de asistencia a los enfermos, desinfectarse las manos con soluciones de sublimado al 1 por 1.000 o de lisol al 20 por 100 una vez salieran del servicio y evitar, en definitiva, toda transgresión del régimen dispuesto por los recintos hospitalarios a nivel interno ${ }^{81}$.

${ }^{81}$ El Correo Español, 2 de mayo de 1904. 
Gráfico 6. Análisis de la mortalidad por tifus exantemático en Madrid por meses y quincenas (1904)

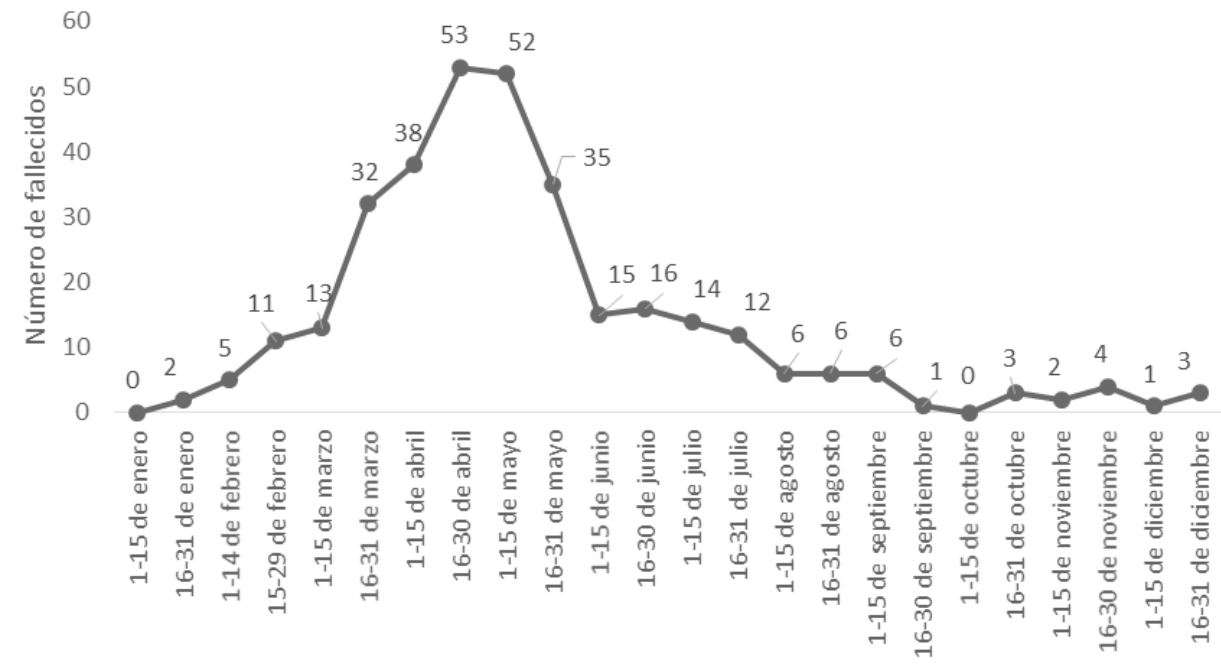

Fuente: AVM, Estadística, Libro de defunciones de Madrid de 1904.

Gráfico 7. Análisis de la mortalidad por tifus exantemático en Madrid por edades (1904)

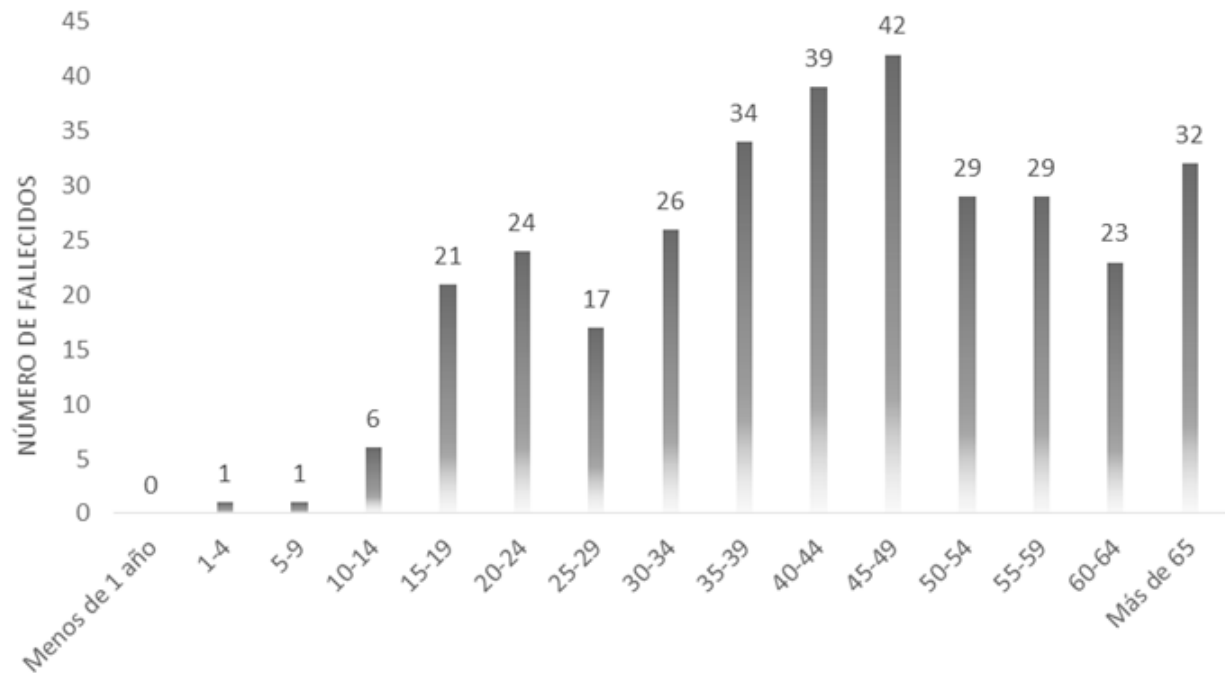

Fuente: AVM, Estadística, Libro de defunciones de Madrid de 1904. 
Gráfico 8. Muertes por tifus exantemático en Madrid por barrios. 1904

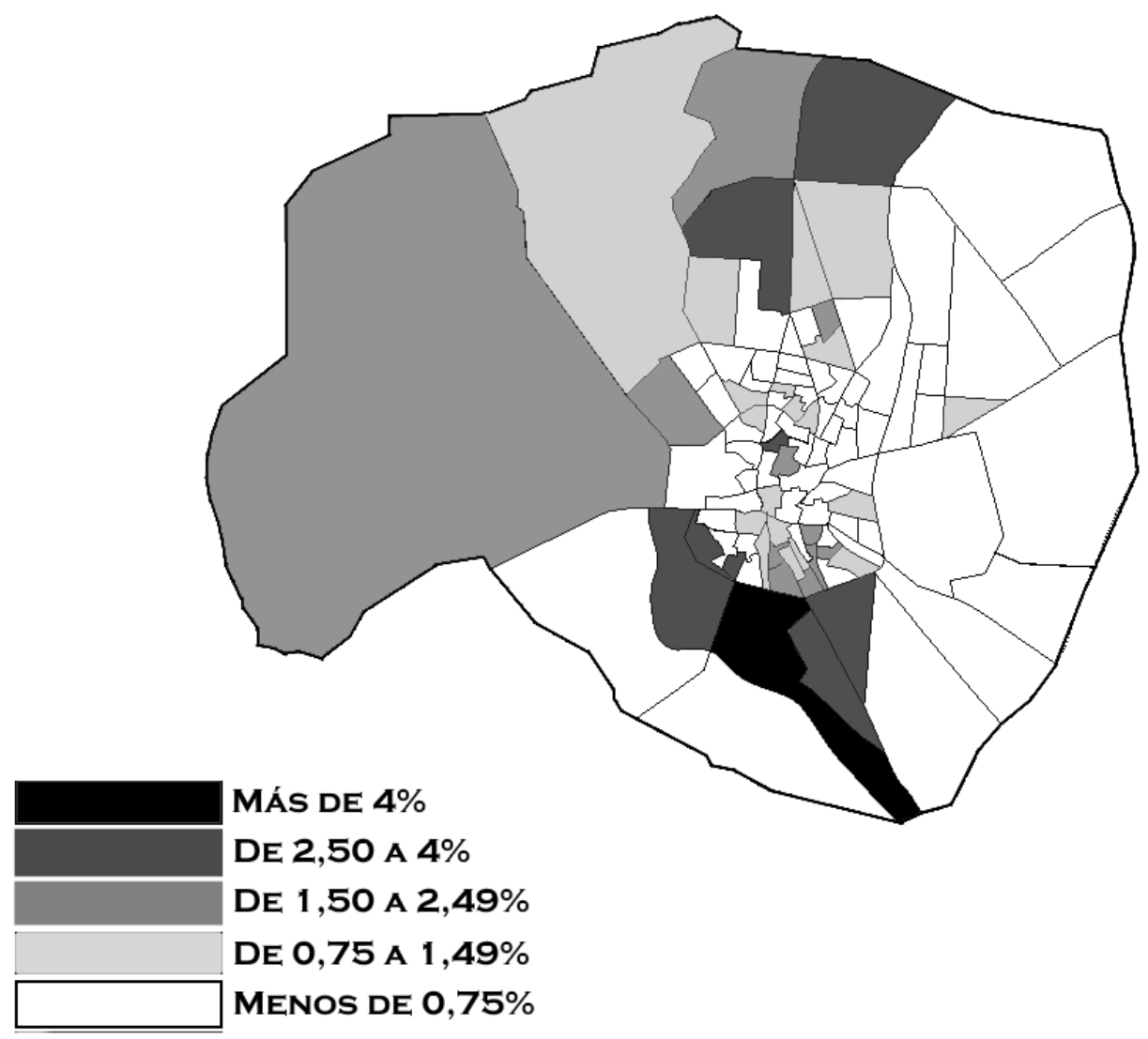

Leyenda: El mapa contabiliza las muertes acaecidas en el Hospital Provincial y en el Hospital del Cerro del Pimiento en función del lugar de procedencia del enfermo, para evitar resultados distorsionados en los distritos de Hospital y Universidad. Fuente: AVM, Estadística, Libro de defunciones de Madrid de 1904.

La epidemia de tifus exantemático en Madrid remitió considerablemente en lo que a intensidad se refiere a partir del verano de 1904. En los meses sucesivos se detectaron nuevos casos en viviendas particulares y focos de infección que no llegaron a expandirse en recintos como el Colegio de la Paz. Las medidas para evitar nuevas invasiones en otros puntos de la ciudad estuvieron siempre directamente vinculadas con las desinfecciones mediante la utilización de formol. Desde las autoridades gubernativas se insistió en la necesidad de continuar con una campaña enérgica en la dirección de los asuntos sanitarios, facilitando los medios necesarios 
para destruir por completo todos los focos que aparecieran ${ }^{82}$. Sin embargo, el último repunte de la enfermedad en el verano de 1905 permite advertir la nula subsanación de las negligencias cometidas en los primeros embates de la epidemia dos años atrás.

Fue a principios de julio de ese año cuando de nuevo se tuvo que admitir por parte de las altas instancias municipales la reproducción de un nuevo brote epidémico. En los primeros días de aquel mes comenzaron a detectarse casos cada vez más numerosos en la barriada comprendida entre las calles de Velázquez, Alcalá y Hermosilla, lo que llevó al gobernador civil, Joaquín Ruiz Jiménez, y a la alcaldía, representada entonces por Eduardo Vincenti, a ordenar con carácter inmediato visitas de inspección a las alcantarillas, retretes y patios interiores de las casas de la ciudad ${ }^{83}$. Sin embargo, la reacción terminó siendo prácticamente idéntica a la tomada en los dos brotes anteriores. Se optó por el recurso de la publicación de un bando municipal relativo a la higienización completa de las casas de Madrid, exigiendo a los propietarios que se indicasen en el mismo la realización inmediata de operaciones de limpieza, reparación de patios y escaleras e instalación de inodoros. Si los caseros se negaban a seguir estas normativas, el consistorio podría ejecutar las obras por su cuenta exigiendo posteriormente a los primeros el abono de los correspondientes gastos. En el caso de que los propietarios se negaran a pagar dichas cuentas, el concejo procedería a incautar los alquileres mensuales percibidos para así resarcirse de las cantidades invertidas en las obras. Desde luego, parecía una medida oportuna para evitar la frecuente reproducción de casos de enfermedades contagiosas no solo ya en viviendas ubicadas en las corralas de los barrios bajos o en las casas de dormir, sino también en las habitaciones que rentaban cantidades comprendidas entre las 25 y las 100 pesetas mensuales en zonas más acomodadas $^{84}$.

El tercer repunte del tifus exantemático en Madrid fue mucho menos significativo que el anterior, pero lo particularmente preocupante no era tanto el número de fallecidos como la reincidente indiferencia mostrada por las autoridades públicas en el enfrentamiento con este problema sanitario. El nulo control de la enfermedad estuvo relacionado con el mantenimiento de una acción social contra la mendicidad que resultó errónea y que solo comenzó a modificarse tras la llegada de republicanos y socialistas al Ayuntamiento de Madrid. La ciudad reunía en aquel momento todas las condiciones apropiadas para el desarrollo de la epidemia, viéndose la hambruna y la miseria social cada vez más reforzadas por la nula operatividad de las políticas urbanas de la época.

\footnotetext{
82 La Época, 8 de marzo de 1905.

83 Diario Oficial de Avisos de Madrid, 5 y 6 de julio de 1905.

${ }^{84}$ El Liberal, 6 de julio de 1905.
} 


\section{CONCLUSIONES}

La epidemia de tifus exantemático analizada en este trabajo ejemplifica a la perfección el carácter desacompasado que mostró el crecimiento poblacional de la ciudad de Madrid en los años finales del siglo XIX y principios del XX con respecto a la evolución de sus condiciones higiénico-sanitarias. No en vano, el inicio de la enfermedad estuvo vinculado al abandono en que quedaron los cada vez más numerosos contingentes de mendigos y pobres llegados a la capital española con anterioridad. Su creciente peso en el seno de la sociedad tenía mucho que ver con las carencias de un mercado laboral incapaz de responder a la fuerte inmigración y carente todavía de un cierto grado de modernización industrial y terciaria, lo que dejaba en el más absoluto desamparo a todos aquellos que no eran capaces de adaptarse a él. A buena parte de ellos les quedó tan solo el recurso a la caridad institucional pública y privada, la cual quedaría organizada de manera deficiente a través de la paulatina apertura de asilos nocturnos.

Uno de los asilos nocturnos que se abrió durante esa etapa fue el de la Montaña del Príncipe Pío, foco originario de la epidemia de tifus exantemático iniciada a finales de abril de 1903. Las dramáticas condiciones de habitabilidad que presentaban los allí acogidos, visibles en su mezcolanza y las enormes deficiencias de las instalaciones, facilitaron los primeros contagios. Sin embargo, la expansión de la enfermedad estuvo ligada a otros aspectos que no competían necesariamente a este depósito de indigentes. Las confusiones en los primeros diagnósticos y los imperdonables errores cometidos en el tratamiento de los enfermos, desviados a un hospital de carácter no epidémico como era el Provincial, son factores decisivos a la hora de explicar esa difusión, en la que también jugaría un protagonismo clave más adelante el hacinamiento de atacados en el Hospital del Cerro del Pimiento y las penosas condiciones presentadas por este último.

Lo que se advierte en líneas generales en el estudio de esta epidemia es la caótica manera con la que las autoridades estatales y municipales trataron de hacer frente a la misma. El descontrol y la escasa organización de la campaña sanitaria fueron responsables del enorme recrudecimiento que mostró la enfermedad entre los meses de marzo y julio de 1904, época en la que quedó expandida por los barrios populares del sur del casco antiguo, por las zonas más miserables y no urbanizadas del Ensanche Sur y por ciertas áreas del norte cercanas al Hospital del Cerro del Pimiento. Sin embargo, las más de quinientas muertes que el tifus exantemático provocó entre abril de 1903 y diciembre de 1905 no marcaron un punto de inflexión en las equívocas políticas de Beneficencia, higiene y salud pública desarrolladas en la ciudad. Apenas seis años después, y en circunstancias muy similares, la epidemia emergería de nuevo en Madrid, reinando de nuevo la improvisación y la falta de planificación preventiva mostrada en esta época. 


\section{BIBLIOGRAFÍA}

Alcaide, R. (1999). La introducción y el desarrollo del higienismo en España durante el siglo XIX. Precursores, continuadores y marco legal de un proyecto científico y social. Scripta Nova. Revista electrónica de geografía y ciencias sociales, 50.

Asociación Matritense de Caridad. (1899). Depósito de Mendigos: Reglamentos. Madrid: Imprenta Municipal.

Asociación Matritense de Caridad. (1903). Memoria descriptiva sobre la formación y régimen de la Asociación Matritense de Caridad fundada en 4 de mayo de 1899. Madrid: Imprenta Municipal.

Bahamonde, Á. y Toro, J. (1978). Mendicidad y paro en el Madrid de la Restauración. Estudios de Historia Social, 7, pp. 353-384.

Baroja, P. (1968). La lucha por la vida. Barcelona: Círculo de Lectores.

Bechah, Y., Capo, C., Mege, J. L. y Raoult, D. (2008). Epidemic Typhus. Lancet Infectious Diseases, 8, pp. 417-426.

Belmás, M. (1882). Discusión acerca de la mortalidad de Madrid. Madrid: Sociedad Española de Higiene.

Bernabéu-Mestre, J. y Galiana, M. E. (2011). El higienismo ante la urban penalty y las causas del atraso sanitario español, 1881-1923. X Congreso de la AEHE: Carmona.

Bernaldo de Quirós, C. y Llanas de Aguilaniedo, J. M.a (1998). La mala vida en Madrid. Zaragoza: Instituto de Estudios Altoaragoneses.

Cañedo, M. (2012). La ciudad medicalizada: epidemias, doctores y barrios bajos en el Madrid moderno. Journal of Spanish Cultural Studies, 13(4), pp. 372-407.

Carballo, B. (2015). El Ensanche Este. Salamanca-Retiro, 1860-1931. Madrid: Catarata.

Chicote, C. (1903). Cartilla del desinfector. Madrid: Imprenta Municipal.

Cirajas, N. Mạ. (1903). Estudio clínico del tifus exantemático. Discurso leído en la sesión inaugural del Ateneo Médico-Quirúrgico. Madrid: Imprenta Ducazcal. 
Cuñat, M. (2011). El higienista Monlau: apuntes para una biografía contextual. European Network on Theory and Practice of Biography. Third International Meeting. Florencia: European University Institute.

Damon, J. (2007). La prise en charge des vagabonds, des mendiants et des clochards: une histoire en mouvement. Revue de droit sanitaire et social, 43(6), pp. 933951.

De Miguel, S. (2016). Madrid, sinfonía de una metrópoli europea. 1860-1936. Madrid: Catarata.

De Miguel, S. (2017). Republicanos y socialistas. El nacimiento de la acción política municipal en Madrid (1891-1909). Madrid: Catarata.

Del Valle, R. (1903). Tifus exantemático. Revista de Medicina y Cirugía Prácticas, 791, pp. 457-466.

Díaz, J. (1865). iAl pueblo!: consejos higiénicos y remedios preventivos contra el cólera-morbo asiático. Madrid: Imprenta del Cascabel.

Díaz, L. (2014). El cólera de 1885 en Madrid: catástrofe sanitaria y conflicto social en la ciudad epidemiada. En Veinticinco años después. Avances en la Historia Social y Económica de Madrid (pp. 463-482). Madrid: Ediciones UAM.

Díaz, L. (2016). Los barrios bajos de Madrid, 1880-1936. Madrid: Catarata.

Fernández García, A. (1979). Enfermedad y sociedad. La epidemia de cólera de 1865 en Madrid. Cuadernos de Investigación Histórica. Fundación Universitaria, 3, pp. 155-186.

Fernández García, A. (1985). Epidemias y sociedad en Madrid. Barcelona: Vicens Vives.

Fernández García, A. (2001). Modelo demográfico y problemas sanitarios. Arbor, 666, pp. 323-342.

García Ferrero, S. (2017), La gripe de 1889-1890 en Madrid (Tesis inédita de doctorado). Centro Superior de Investigaciones Científicas, Madrid.

González Campo, J. (1904). Nota clínica de la actual epidemia de tifus exantemático. Revista de Especialidades Médicas, año VII, pp. 245-252. 
González, M. J. (1854). Reflexiones sobre el cólera-morbo asiático. Madrid: Imprenta de Alejandro Fuentenebro.

Hamonet, M. A. (1997). Les épidémies de typhus dans le Royaume-Uni au XIXe siècle (Tesis inédita de doctorado). Université Sorbonne Nouvelle-Paris III, Paris.

Hauser, P. (1902). Madrid bajo el punto de vista médico-social. Madrid: Sucesores de Rivadeneyra.

Hudemann-Simon, C. (2017). La conquista de la salud en Europa. 1750-1900. Madrid: Siglo XXI.

Jimeno, J. (1886). El cólera en España durante el año 1885. Madrid: El Correo.

Jimeno, J. (1886). Madrid, su población, natalidad y mortalidad. Madrid: El Correo.

Katz, L. (2015). L'Avènement du Sans-Abri. Les asiles de nuit, 1871-1914. Paris: Libertalia.

Krause, M. (1984). Madrid, 1900. La ciudad de la miseria. Historia 16, 101, pp. 1524.

Lartiga, J. (1854). Cólera morbo asiático: tratamiento preservativo y curativo de esta enfermedad. Madrid: Imprenta de Higinio Reneses.

López Castellano, F. (2010). El buen samaritano no sabía economía política: de la primera ley de Beneficencia al intervencionismo científico (1822-1920). Revista de la Historia de la Economía y de la Empresa, 4, pp. 21-49.

Méndez Álvaro, F. (1882). Resumen de la discusión sobre la mortalidad en Madrid. Madrid: Imprenta de Enrique Teodoro.

Monmeneu, J. (1904). La epidemia de viruela de 1903-4. Madrid: Imprenta y Librería de Nicolás Moya.

Moro, J. (1986). Francisco Méndez Álvaro: la higiene española en el siglo XIX. Madrid: Junta de Castilla y León.

Pallol, R. (2015). El Ensanche Norte. Chamberí, 1860-1931. Madrid: Catarata. 
Pinto, V. (2002). Pobreza y beneficencia en el Madrid del siglo XIX. En VV. AA., Madrid, tres siglos de una capital, 1702-2002 (pp. 187-200). Madrid: Fundación Caja Madrid.

Porras Gallo, M. a I. (2002). Un acercamiento a la situación higiénico-sanitaria de los distritos de Madrid en el tránsito del siglo XIX al XX. Asclepio, 54(1), pp. 219250.

Puerto, F. J. (1980). La epidemia de cólera de 1834 en Madrid. Aspectos sanitarios y socioeconómicos. Estudios de Historia Social, 15, pp. 9-61.

Quintal, D. (1996). Historical aspects of the Rickettsioses. Clinics in Dermatology, 14(3), pp. 237-242.

Revenga, R. (1901). La muerte en Madrid. Madrid: Imprenta de Enrique Teodoro.

Rísquez, F. A. (1903). A propósito del tifus. Revista de Especialidades Médicas, año VI, pp. 267-269.

Rodríguez Ocaña, E. (1992). Por la salud de las naciones: higiene, microbiología y medicina social. Madrid: Akal.

Rodríguez Ocaña, E. (2001). Confort, ornementation, hygiène. Modernisation urbaine et hygiènisme dans I'Espagne du XIXème siècle. En Pierre Bourdelais (dir.), Les Hygiénistes : enjeux, modèles et pratiques (pp. 297-318). Paris, Éditions Belin.

Rodríguez Ocaña, E. (2007). Carlos María Cortezo Prieto (1850-1933) y el tifus exantemático: un descubrimiento inexistente. En Ricardo Campos, Luis Montiel y Rafael Huertas (coord.), Medicina, ideología e historia en España (siglos XVIXXI) (pp. 125-134). Madrid, CSIC.

Schoendorff, J. (1988). El Dr. Carlos María Cortezo y su obra (1850-1933). Madrid: Editorial Complutense.

Úbeda, J. (1900). Medios de disminuir la mortalidad en Madrid. Madrid: Imprenta del Cuerpo de Administración Militar.

Urquijo, J. R. (1983). Madrid ante la epidemia de cólera de 1854-1856. Asclepio, 35, pp. 27-52. 
Vicente, F. (2015). El Ensanche Sur. Arganzuela, 1860-1931. Los barrios negros. Madrid: Catarata.

Vidal, F. (1992). ¿Qué hacemos con los pobres? El origen del Asilo de San Bernardino (1834). Espacio, Tiempo y Forma. Serie V. Historia Contemporánea, 5, pp. 305316.

Wilder, R. M. (1911). The Problem of Transmission in Typhus Fever. Journal of Infectious Diseases, 9(1), pp. 9-101. 
Página intencionadamente en blanco. 